\title{
En los orígenes de El Argar: la cerámica decorada como indicador arqueológico de su espacio social inicial ${ }^{\star}$
}

\author{
The origins of El Argar: decorated ceramics as an archaeological indicator of its initial \\ social space
}

Mauro S. Hernández Pérez ${ }^{a}$, Juan A. López Padilla ${ }^{\mathrm{b}}$ y Francisco Javier Jover Maestre Con puntillados e incisiones aparecen también las
primeras piezas argáricas a pesar de que hasta ahora
se las había creído carentes de toda decoración

(Figueras Pacheco 1939: 110)

\section{RESUMEN}

Se presenta una nueva propuesta sobre la dimensión espacial y temporal de los inicios del grupo argárico, a partir de los datos aportados por las actuaciones arqueológicas realizadas en el ámbito del Bajo Segura y Bajo Vinalopó durante esta última década, y de la evaluación de materiales arqueológicos y secuencias estratigráficas obtenidas en yacimientos excavados en la zona entre los años 1980 y 1990. Las dataciones radiocarbónicas y el análisis detenido del registro cerámico correspondiente a los estratos basales de yacimientos como Laderas del Castillo, Tabayá, Cabezo Pardo y Caramoro I nos permiten plantear la conformación de las bases materiales de la sociedad argárica en un territorio más amplio que el hasta ahora considerado como "área nuclear" de El Argar, en la que quedarían incluidas no solo la cuenca de Vera y el valle del Guadalentín, sino también la Vega Baja del Segura y el Bajo Vinalopó.

\begin{abstract}
We suggest a new approach to the spatial and temporal dimensions of the beginnings of the Argaric group. This is based on the data provided by the archaeological work carried out during the last decade in the lower Segura and lower Vinalopo basins, and from the study of the archaeological
\end{abstract}

materials and stratigraphic sequences obtained at sites in the area excavated in the 1980s and 1990s. Radiocarbon dating and careful analysis of the ceramic record from the basal strata of Argaric sites such as Laderas del Castillo, Tabayá, Cabezo Pardo and Caramoro I allow us to consider the formation of the material bases of the Argaric society in a wider territory than the one until now considered its "nuclear area". This would now include not only the Vera Basin and the Guadalentin Valley, but also the lower Segura and lower Vinalopó basins.

Palabras clave: Edad del Bronce; El Argar; secuencia estratigráfica; carbono 14; cerámica decorada; frontera; sureste península ibérica.

Key words: Bronze Age; El Argar; stratigraphic sequence; radiocarbon; decorated pottery; frontier; Southeast Iberian Peninsula.

\section{INTRODUCCIÓN}

Determinar los orígenes de los grupos arqueológicos y establecer sus dimensiones espaciales y temporales han constituido desde siempre dos objetivos esenciales de la arqueología (Martínez Navarrete 1989;

\footnotetext{
* El presente trabajo ha sido realizado en el marco del proyecto de investigación "Espacios sociales y espacios de frontera durante el Calcolítico y la Edad del Bronce en el Levante de la península ibérica" (HAR2016-76586-P), financiado por el Ministerio de Economía y Competitividad del Gobierno de España.

a Dpto. de Prehistoria, Arqueología, Historia Antigua, Filología Griega y Filología Latina. Universidad de Alicante. Carretera de San Vicente s/n. 03690 San Vicente del Raspeig. Alicante. España. Correo e.: mauro.hernandez@ua.es https://orcid.org/0000-0001-8225-4730

b Museo Arqueológico Provincial de Alicante. MARQ. Plaza Gómez Ulla 13. 03013 Alicante. España. Correo e.: japadi@diputacionalicante.es https://orcid.org/0000-0002-1506-4731

c Instituto Universitario de Investigación en Arqueología y Patrimonio Histórico INAPH. Universidad de Alicante. Carretera de San Vicente s/n. 03690 San Vicente del Raspeig. Alicante. España. Correo e.: javier.jover@ua.es https://orcid.org/0000-0001-5213-2361

Recibido 16-IX-2020; aceptado 11-I-2021.
} de uso y distribución "Creative Commons Reconocimiento 4.0 Internacional" (CC BY 4.0) 
Trigger 1990). En el caso de la península ibérica, el temprano reconocimiento de la "cultura" de El Argar (Siret y Siret 1890; Tarradell 1946) y su singular registro arqueológico -en especial, sus ajuares funerariosla convirtieron en el centro de atención de un ingente número de investigadores.

Décadas de estudios dieron lugar a posturas enfrentadas en cuanto a la explicación de su origen, pero todas asumían y compartían la idea de un "área nuclear" argárica, situada en torno a la cuenca de Vera y del Guadalentín. Desde allí, donde habría surgido lo que reconocemos arqueográficamente como El Argar, lo "argárico" se habría extendido a nuevos espacios geográficos siguiendo un modelo de gradiente cronológico. Esta interpretación tradicional cobraba sentido en el marco conceptual de "área cultural" propuesto por C. Wissler (1927), profusamente empleado por la escuela norteamericana de antropología de F. Boas.

En estudios clásicos históricos de principios del siglo XX, el área nuclear -nuclear core- se definió como "el área en la cual o en torno a la cual se origina un Estado" (Whittlesey 1920: 597). Nuestro concepto, más allá del reconocimiento de una nueva materialidad, implica considerar que dicho espacio geográfico constituyó el espacio social de la nueva entidad argárica, como contenido esencial de una nueva sociedad concreta (Bate 1998; Flores 2007) con unas relaciones sociales de producción y reproducción normativizadas.

En la actualidad disponemos de más y mejores datos con los que construir un modelo más definido del desarrollo temporal y espacial de la sociedad argárica (Molina González et al. 2004; Lull et al. 2009; López y Jover 2014). En el presente artículo realizamos una propuesta acerca no solo de la cronología, sino del territorio específico donde se fraguó su constitución inicial a partir de la cerámica decorada, un elemento poco reconocido de su materialidad.

\section{EL ARGAR ¿CÓMO? ¿CUÁNDO? ¿DÓNDE?}

La cuestión de los orígenes de El Argar ha ocupado siempre un lugar central en la investigación (Siret y Siret 1890). Durante casi un siglo, se confrontaron básicamente dos interpretaciones radicalmente opuestas: la que relacionaba su surgimiento con la llegada de inmigrantes centroeuropeos o del Mediterráneo central u oriental y la que lo creía resultado de un proceso de desarrollo local, generado a partir del 'progreso' autóctono de las poblaciones calcolíticas del sureste (Martínez Navarrete 1989: 340-358).

El elemento clave alrededor del cual ha pivotado durante décadas este debate ha sido, por supuesto, la indiscutida personalidad de la fenomenología argárica. Luis Siret pasó de atribuir primero a la originalidad del "pueblo árgaro" todas las innovaciones que evidenciaban sus hallazgos (Siret y Siret 1890: 333), a considerarlas después una consecuencia de la llegada de pueblos celtas (Siret 1907: 93). Esta hipótesis, sin embargo, soslayaba la ausencia de testimonios arqueológicos que permitieran jalonar tal desplazamiento desde el corazón de Europa hasta la península ibérica (Bosch 1932: 169).

En esencia, la controversia giraba en torno a una serie de elementos, considerados intrínsecamente argáricos, que artefactualmente presentaban, en apariencia, vinculaciones geográficas contrapuestas: por un lado, las alabardas de metal y los vasos carenados parecían reclamar relaciones con el centro y occidente de Europa y, por otro, los referentes más claros de los enterramientos en urnas y las copas de cerámica se encontraban en el Mediterráneo oriental. A principios del siglo $\mathrm{XX}$, solo unos pocos investigadores defendían aún un origen en la península ibérica, por ejemplo, para las alabardas de metal (Schmidt 1915: 14), mientras que el número de valedores de las tesis opuestas iba claramente en aumento.

La hipótesis de Déchelette (1910: 80), apenas matizada después por otros investigadores (Siret 1913: 150162; Martínez Santa-Olalla y Sáez 1947: 156; Evans 1958: 52), proponía que tanto el grupo de Aunjetitz como el de El Argar eran independientes entre sí. Sus concomitancias serían resultado del contacto de ambos grupos con las poblaciones del Egeo, al constituir sus territorios puntos neurálgicos en las dos rutas abiertas hacia occidente a comienzos de la Edad del Bronce: a través del interior del continente, el de Aunjetitz, y del Mediterráneo y la costa atlántica, el de El Argar.

Frente a esta idea P. Bosch (1920: 166; 1932: 168) y G. y V. Leisner (1949: 364) defendieron un desarrollo local. Para ellos, El Argar habría evolucionado localmente a partir de la llamada Cultura de Almería, en un lugar del sureste que no era posible precisar, y de forma independiente a Los Millares.

Los argumentos expuestos por E. Sangmeister (1963) acerca de su célebre "movimiento de reflujo campaniforme", llevaron después a B. Blance (1964) a vincular el origen de El Argar con la aparición en la península de grupos campaniformes tardíos, de origen centroeuropeo, sobre los que actuarían poblaciones mediterráneas llegadas más tarde (Schubart 1976).

Con el fin de la dictadura franquista, el relato difusionista fue atemperándose (Schubart y Arteaga 1986) a medida que los procesos de desarrollo locales iban tomando protagonismo en las nuevas hipótesis, planteadas tanto desde el procesualismo (Chapman 1991) como desde diversas posiciones marxistas (Lull 1983; Gilman 1987; Lull y Risch 1996; Arteaga 2000, entre otros). En las últimas décadas, la cuestión del origen ha dejado de estar en el epicentro de la investigación. 
Se asume de forma mayoritaria un surgimiento y desarrollo autóctono de El Argar, pero no ajeno a la circulación de personas, ideas, materias primas y objetos, en el ámbito del Mediterráneo y Europa, tal y como avalan los últimos estudios (Lull et al. 2014; Aranda et al. 2015; Montero et al. 2019; Knipper et al. 2020, entre otros).

Lo cierto es que a lo largo de más de 100 años de investigación las posiciones adoptadas acerca del origen de El Argar giraron en torno a su manifiesto carácter rupturista con respecto al Calcolítico precedente. Los cambios en la morfología de las viviendas, la institucionalización del enterramiento individual (y doble) en el interior de los recintos habitados o la aparición de un repertorio restringido y carente de decoración de formas cerámicas (Schubart 1975), entre otros, han sido considerados generalmente elementos disruptivos, en abierta oposición a las tradiciones calcolíticas de viviendas circulares, del enterramiento colectivo y vajillas decoradas con motivos simbólicos o con barrocas combinaciones de impresiones, incisiones y puntillados (Molina y Cámara 2004; Lull et al. 2009, 2015a).

Calibrar el calado y cronología de esta "disrupción argárica" resultaba, por otro lado, muy difícil mientras el grueso del registro estuvo conformado casi exclusivamente por ajuares funerarios o por datos de excavaciones antiguas, con insuficiente o incluso inexistente información estratigráfica (Bosch 1954; Blance 1971; Schubart 1975). Hoy las bases documentales disponibles se han visto ampliamente incrementadas (González Marcén 1994; Castro et al. 1996; Molina González et al. 2004; Aranda et al. 2015, entre otros). Los ensayos más recientes no han logrado resolver por completo el problema pero, al menos, lo han reducido a señalar como escenario más probable una desarticulación de los grupos calcolíticos previa a la conformación de El Argar, sin descartar por completo un breve solapamiento temporal entre una y otra (Lull et al. 2010: 91; 2015a: 371, fig. 3).

Paralelamente, la distribución geográfica de las dataciones argáricas más antiguas venían a corroborar la hipótesis que, desde el siglo pasado, proponía un territorio "nuclear" en la cuenca de Vera y valle del Guadalentín (Bosch 1932; Cuadrado 1947; Tarradell 1965, entre otros) desde donde se habría experimentado una posterior expansión a una amplia zona del sureste de la península (Arribas 1976: 152; Arteaga y Schubart 1980: 268; Arteaga 1993: 199, 2000: 135; Molina y Cámara 2004: 457; Aranda et al. 2015). De este modo, el radiocarbono, en combinación con el análisis de la distribución de la materialidad argárica en el territorio, estaba finalmente en condiciones de revelar también los estadios de desarrollo de este modelo expansivo (González Marcén 1994; Castro et al. 1996) que fue perfilándose a lo largo de las décadas siguientes (Ar- teaga 2000; Lull et al. 2009: 228), pero que en todo momento ha mantenido la idea de un "área nuclear" restringida a la cuenca de Vera y al valle del Guadalentín (Lull et al. 2015a: 373, fig. 5).

Sin embargo, las investigaciones llevadas a cabo en territorios considerados en principio marginales e, incluso, fronterizos (Tarradell 1963; Hernández 1986; Jover y López 1997) vienen a refutar esta hipótesis y a plantear un nuevo escenario en relación con la formación y desarrollo de lo que reconocemos como sociedad argárica.

\section{LAS CERÁMICAS DECORADAS DE EL ARGAR INICIAL EN SU TERRITORIO NORORIENTAL}

A la vez que se llevaban a cabo importantes trabajos de excavación y estudios en asentamientos argáricos como Fuente Álamo (Schubart et al. 2000; Risch 2002; Schuhmacher y Schubart 2003; Schubart 2012), Gatas (Castro et al. 1999), Peñalosa (Contreras 2000; Contreras et al. 2014; Alarcón 2010), Tira del Lienzo (Lull et al. 2015b), La Almoloya (Lull et al. 2015c) y La Bastida (Lull et al. 2015b), en el sur de Alicante se han ido desarrollado diversos proyectos de investigación que, aunque más modestos, han obtenido algunos resultados reseñables (Hernández 2009; López 2014; Jover et al. 2019a (Fig. 1). Tres son los yacimientos que han proporcionado información relevante sobre la cronología y caracterización de las primeras evidencias argáricas.

\subsection{Tabayá (Aspe, Alicante)}

Conocido desde principios del siglo XX, las excavaciones llevadas a cabo por la Universidad de Alicante entre 1987 y 1991 confirmaron su amplia secuencia estratigráfica (Hernández 2009). Mediante la evaluación conjunta de los datos estratigráficos y de los contextos de habitación documentados se ha podido reconocer una serie sucesiva de unidades sedimentarias, relacionadas estratigráficamente con conjuntos coherentes de estructuras y materiales, que se corresponden, a su vez, con las cinco fases arqueológicas identificadas. Los niveles 10 y 11 pertenecen a la fase I o inicial, donde se documentan las primeras edificaciones, asentadas directamente sobre la roca. Una falange de Bos taurus proveniente de los estratos de abandono de una de estas viviendas -Beta 487171: $3680 \pm 30 \mathrm{BP}$ - proporcionó una fecha cuyo mayor porcentaje de probabilidad se sitúa entre 2130-2010 cal BC (Hernández et al. 2019: 51, tab.1).

En la base del corte 8, sobre parte de un pavimento asociado a un tramo de muro dispuesto en sentido

Trab. Prehist., 78, N. ${ }^{\circ}$ 1, enero-junio 2021, pp. 86-103, ISSN: 0082-5638

https://doi.org/10.3989/tp.2021.12266 


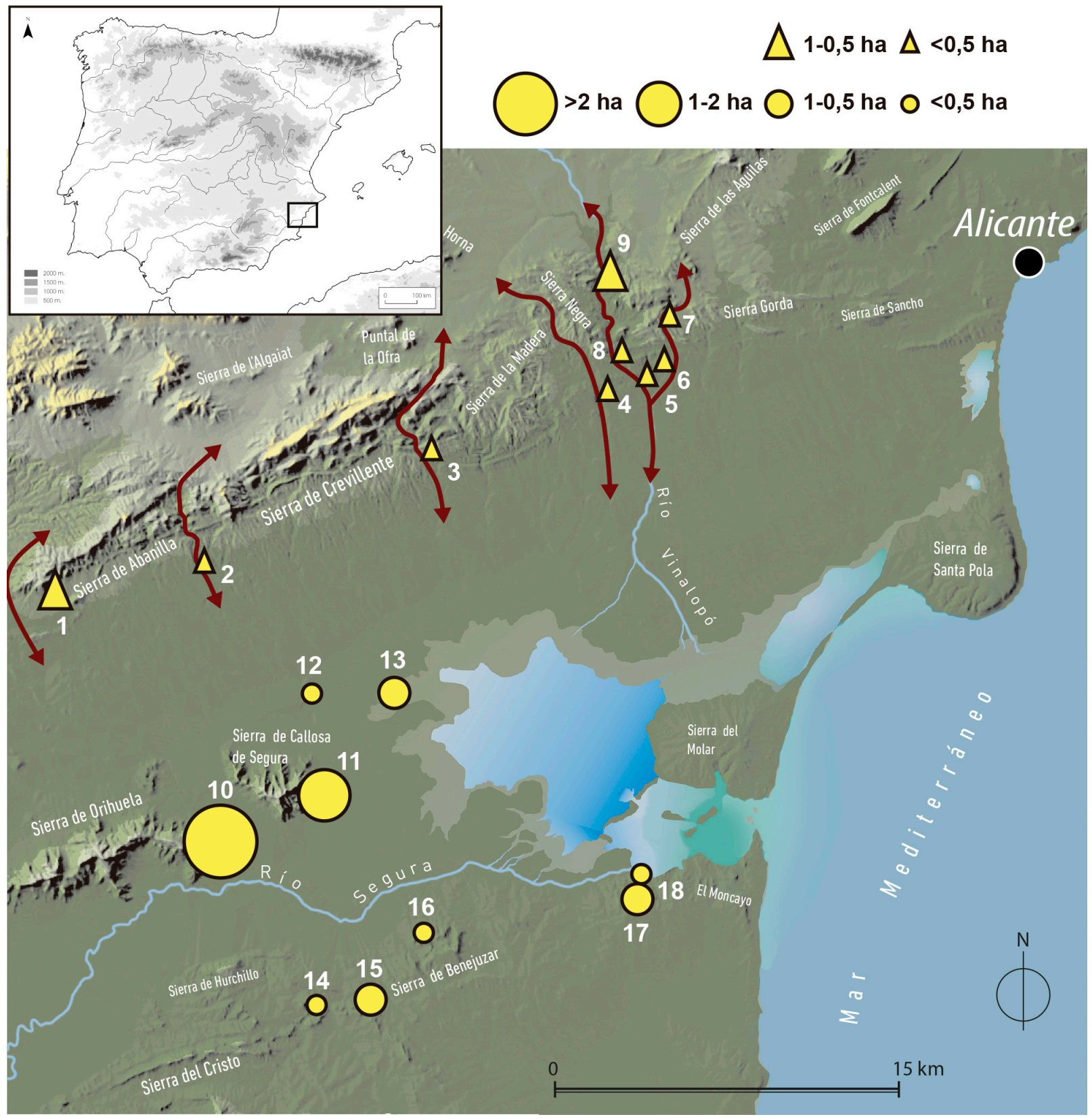

Fig. 1. Mapa físico de la Vega Baja del Segura y del Bajo Vinalopó, con indicación de los principales relieves y cursos fluviales, así como de las áreas inundables existentes hacia $2000 \mathrm{cal} \mathrm{BC}$, a partir de la propuesta de C. Ferrer (2010). Con triángulos y en secuencia numérica se señalan los asentamientos localizados a lo largo de la frontera septentrional argárica, y con círculos el resto, correspondiendo el tamaño de los símbolos con la superficie relativa estimada para cada grupo. Con flechas se indican las principales vías de comunicación entre la cuenca media del Vinalopó y la Vega Baja del Segura. Asentamientos: 1. El Morterico; 2. Loma de Hurchillo; 3. Pic de Les Moreres; 4. Barranco de los Arcos; 5. Caramoro I; 6. La Moleta; 7. Animeta; 8. Puntal del Búho; 9. Tabayá; 10. San Antón; 11. Laderas del Castillo; 12. Cabezo del Pallarés; 13. Cabezo Pardo; 14. Cabezo del Rosario; 15. Cabezo del Moro; 16. Cabezo del Mojón; 17. Cabezo Soler; 18. Cabezo de las Particiones. Elaboración propia a partir de base cartográfica MDT200 y BCN200 (Fuente: IGN-CNIG). En color en la edición electrónica.

noreste-suroeste (Hernández 2009: 163, fig. 2), se registraron fragmentos de varios recipientes cerámicos decorados con líneas incisas y puntillado (Hernández
1997: 102, fig. 1) que desde un primer momento se relacionaron con las vasijas decoradas del Promontori de Aigua Dolça i Salada, en Elche. La pieza más relevante 

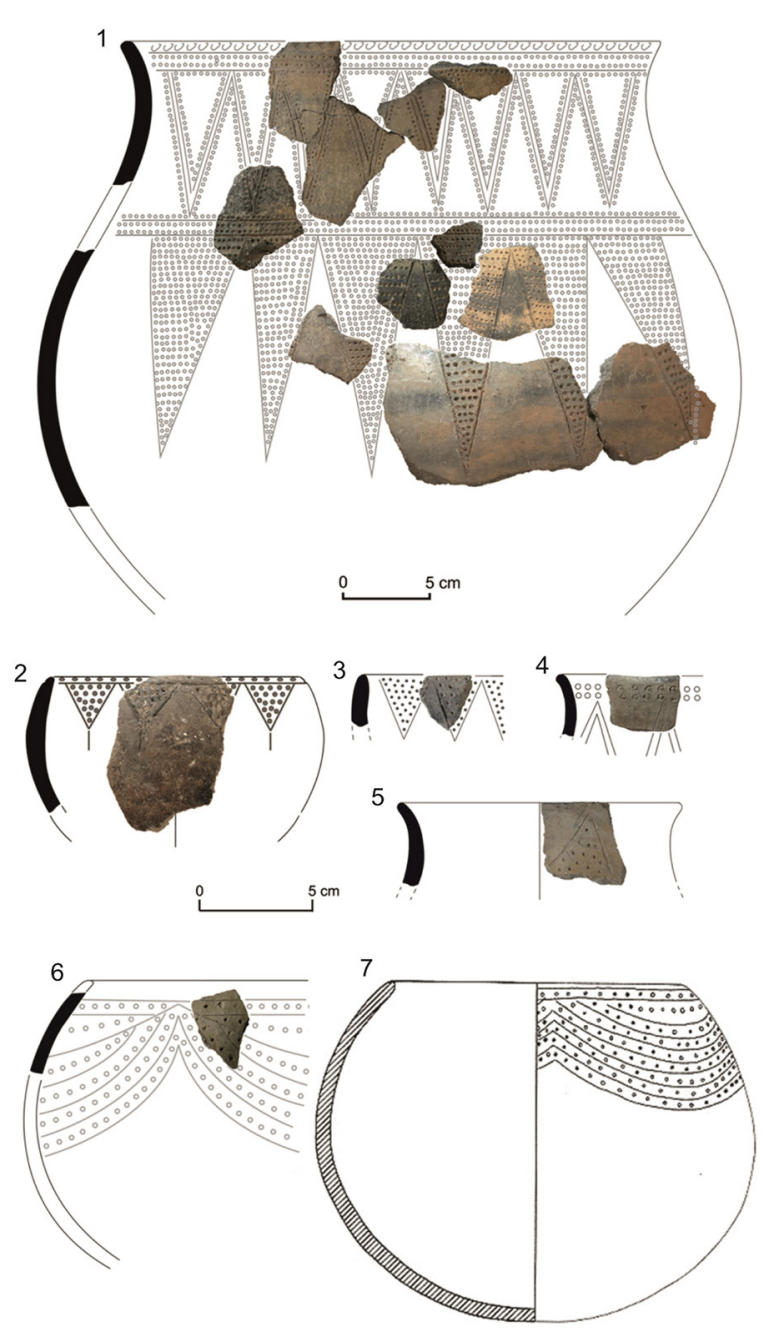

Fig. 2. Cerámicas con decoración incisa y puntillada. Tabayá (Aspe, Alicante): 1-6, Lugarico Viejo (Antas, Almería): 7, según Schubart y Ulreich (1991: taf. 124.1). En color en la edición electrónica.

es un vaso con cuello y borde exvasado, de perfil en $\mathrm{S}$, profusamente decorado (Fig. 2.1). El motivo principal consiste en una franja superior con un zigzag horizontal de dos líneas incisas enmarcadas por otras en puntillado. Más abajo, de la zona que separa el cuello del cuerpo arranca una serie de triángulos invertidos, muy alargados, delimitados por líneas incisas y completamente rellenos de puntillado.

El resto son en su mayoría fragmentos de cuencos, en los que se repite el tema de los triángulos incisos rellenos de puntillados o de rayados verticales u oblicuos, a veces combinados con líneas incisas continuas que suelen alternar con líneas de puntillado (Fig. 2.2-5). En algunos aparecen, en cambio, solo líneas de puntos que podrían estar dibujando motivos en zigzag. Un fragmento en particular, con una serie inclusiva de lí- neas curvas incisas alternadas con líneas de puntillado en paralelo (Fig. 2.6), se asemeja enormemente al de uno de los vasos hallados por los Siret en Lugarico Viejo (Fig. 2.7).

\subsection{Laderas del Castillo (Callosa de Segura, Alicante)}

Ampliamente explorado en el pasado (Colominas 1931; Furgús 1937), desde 2013 se vienen realizando campañas de excavación de carácter anual (López et al. 2017) que han confirmado las antiguas noticias sobre la presencia de cerámicas decoradas en el yacimiento (Åberg 1921: 142, fig. 181). Los hallazgos que permiten un seguimiento estratigráfico más preciso se concentran en la zona II (Fig. 3). Aquí la secuencia se inicia con el alzado de un gran muro de aterrazamiento, asociado a una construcción de aspecto turriforme de planta subrectangular, casi cuadrada (B2), que por su disposición con respecto al muro-terraza bien pudo hacer también las veces de contrafuerte. Sobre la terraza se construyó un edificio alargado (C), de unos $4 \mathrm{~m}$ de anchura, con uno de sus extremos de forma absidal o, al menos, con esquinas redondeadas, levantado con paredes de barro amasado sobre un zócalo de piedras muy bajo. Por su cara exterior, la pared estaba jalonada por una serie equidistante de huecos para calzar postes de madera, de los que se conservaban cinco. Se localizaron sobre el pavimento dos ollas y un pequeño vaso con bellotas carbonizadas, aplastadas contra el suelo. Ambos carecían de decoración, pero en el extremo septentrional de la vivienda, en contacto con la estructura turriforme B2, necesariamente contemporánea, aparecieron varios recipientes con decoración incisa. Uno de ellos corresponde al cuerpo de una vasija, probablemente de perfil en S (Fig. 4.2).

Entre los niveles de derrumbe de los edificios $\mathrm{C}$ y B2, afectados en parte por otra construcción de tipo turriforme -B1- levantada sobre ellos, se localizaron algunos fragmentos de otro recipiente de similares características, así como parte de un cuenco muy mal conservado, decorado con tres líneas incisas horizontales próximas al borde y una serie de triángulos invertidos rellenos con un rayado oblicuo, con restos de una sustancia blanquecina en su interior (Fig. 4.1).

Las dataciones radiocarbónicas permiten fijar la construcción de la terraza en un momento anterior a 2200 cal BC -Beta-397231: $3800 \pm 30 \mathrm{BP}-$ a partir de un fragmento de hueso de oveja localizado entre el material de relleno. La destrucción del edificio $\mathrm{C}$ puede también situarse con cierta precisión gracias a la datación de las bellotas carbonizadas halladas sobre el pavimento -LTL-13680A: $3766 \pm 35$ BP y Beta360124: $3710 \pm 30 \mathrm{BP}-$ alrededor de 2150 cal BC. Por

Trab. Prehist., 78, N. ${ }^{\circ}$ 1, enero-junio 2021, pp. 86-103, ISSN: 0082-5638

https://doi.org/10.3989/tp.2021.12266 


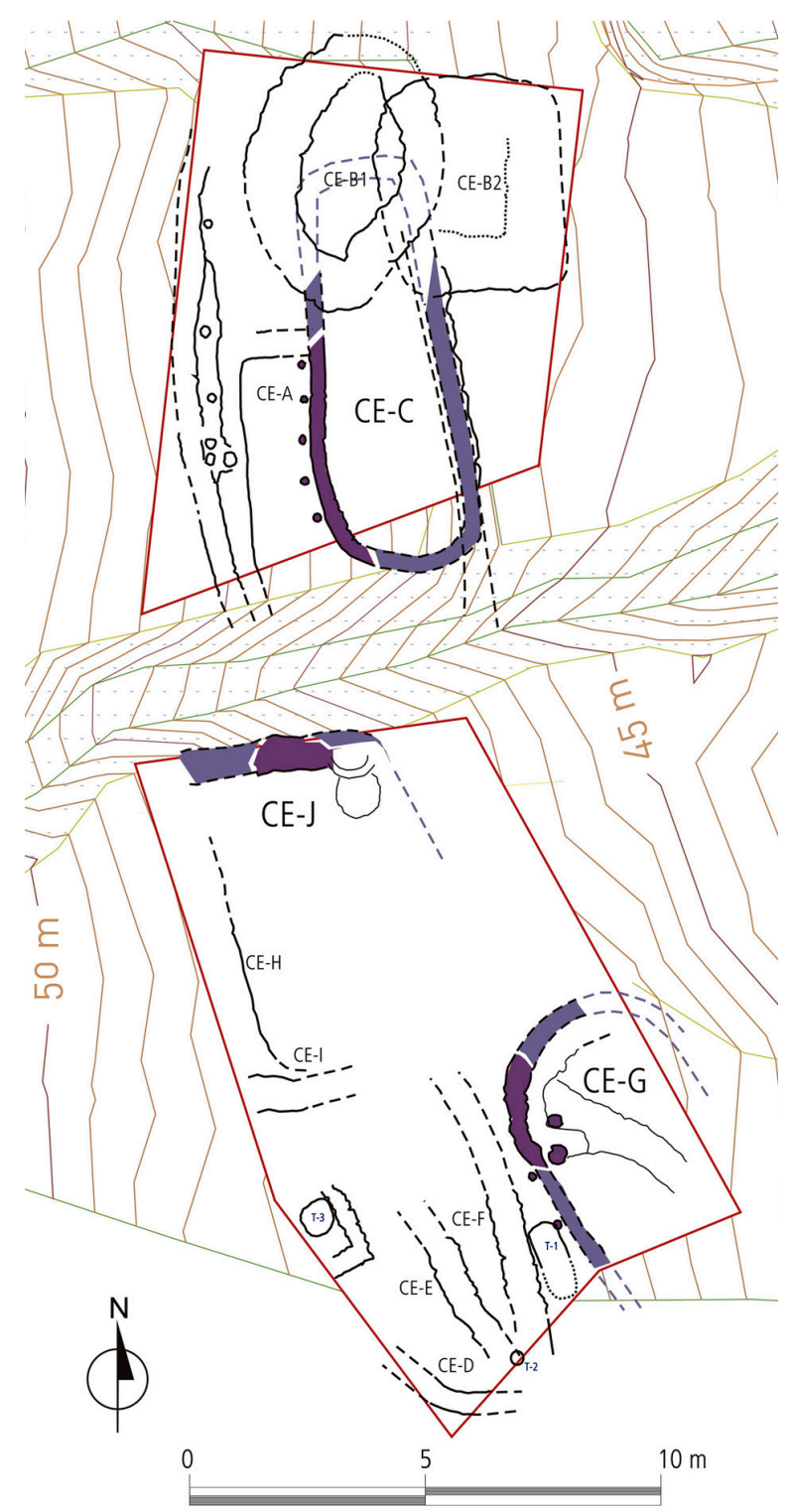

Fig. 3. Planta de Laderas del Castillo (Callosa de Segura, Alicante) correspondiente al Sector 3 de las Zonas I y II. Se resaltan los complejos estructurales (CE) interpretados como viviendas pertenecientes a la fase inicial de la secuencia de ocupación del asentamiento. En tono más intenso los lienzos de muro conservados, y más claro el trazado que se infiere a partir de estos. En color en la edición electrónica.

último, una semilla de cereal carbonizada procedente del mismo nivel en el que apareció el cuenco decorado con triángulos incisos rellenos de pasta blanca -LTL13679A: $3684 \pm 45 \mathrm{BP}$ - arrojó una fecha en torno a $2050 \mathrm{cal} \mathrm{BC}$.

A la última fase arqueológica documentada en el Sector 3 corresponden los restos de un edificio -A-, ya completamente construido con mampostería, con calzos de poste al interior, y un largo banco corrido adosado a la pared occidental (López et al. 2018). Entre el variado repertorio de materiales hallado se cuenta un fragmento de cuenco cuya decoración puntillada repetía el modelo decorativo de los triángulos invertidos junto al borde, pero sin líneas incisas que los delimiten (Fig. 4.7). Las dataciones radiocarbónicas -LTL-13677A: $3679 \pm 40$ BP y Beta-360123: 3590 $\pm 30 \mathrm{BP}$ - señalan un horizonte cronológico en torno a 2000 cal BC para la destrucción de esta vivienda. Las demás cerámicas decoradas (Fig. 4.3-6) muestran un repertorio decorativo similar, pero no cuentan con un contexto arqueológico tan preciso.

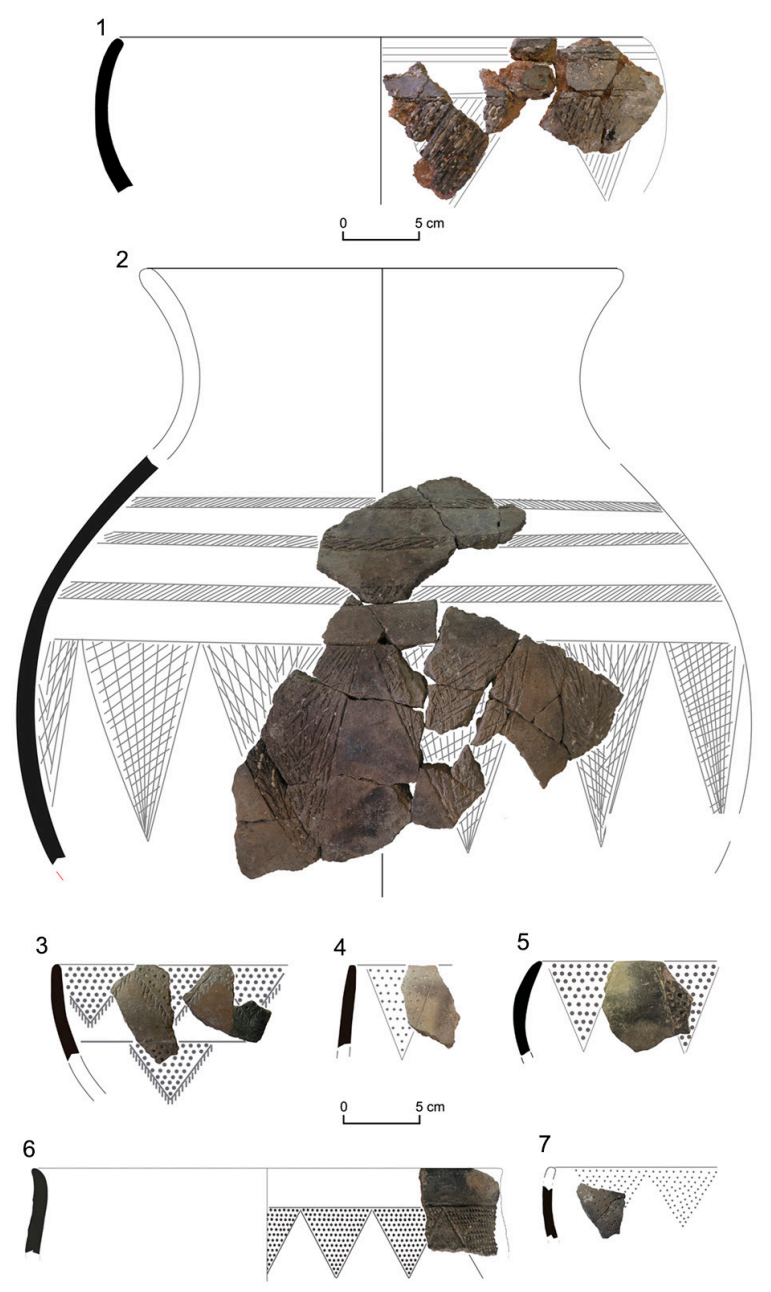

Fig. 4. Laderas del Castillo (Callosa de Segura, Alicante): 1-2. Recipientes con decoración incisa localizados en los edificios C y B2; 3-7. cuencos con triángulos invertidos incisos rellenos de puntillado impreso. En color en la edición electrónica. 


\subsection{Illeta dels Banyets (El Campello, Alicante)}

Del yacimiento se conocía ya un amplio conjunto de cerámicas prehistóricas (Figueras 1934, 1950), algunas de las cuales, según su excavador, habían sido decoradas con incisiones "hechas con un palillo" (Figueras 1934: 19). Una serie de notas mecanografiadas, que se han conservado ${ }^{1}$, permiten deducir que la mayor parte de estos recipientes proviene de la recogida de materiales realizada en 1943 durante el desmonte y voladura de una parte del yacimiento (Figueras 1950: 33).

El estudio de estos materiales cerámicos a finales del siglo pasado (Simón 1988, 1997) los situaba en el llamado "Bronce Tardío" del sureste. La presencia de fuentes de carena alta y bordes engrosados, y de fragmentos con decoraciones con la técnica de punto y raya, e incluso de cerámicas excisas, justificaba sobradamente considerar esta atribución, especialmente cuando entre los motivos decorativos de estas cerámicas tardías figuran también los triángulos invertidos rellenos de puntillado, aunque mayoritariamente realizados con la técnica del punto y raya o "boquique" (Molina y Pareja 1975: 49-50; Molina González 1978: 204).

Los trabajos arqueológicos realizados entre 2000 y 2001 en el yacimiento (Soler 2006) confirmaron la presencia de materiales tardíos con este tipo de decoraciones (Belmonte y López 2006: 187, fig. 91), aunque no vasijas incisas con la técnica exclusiva del puntillado, del estilo que mostraban las halladas por F. Figueras Pacheco. Ahora, en cambio, estas parecían mucho más cercanas en cuanto a su forma -cuencos globulares o esféricos, de bordes rectos o entrantes- y a técnica decorativa -triángulos invertidos conformados exclusivamente por puntillado- a las vasijas decoradas de los niveles de ocupación iniciales de Tabayá y Laderas del Castillo (Fig. 5).

\section{VASIJAS DECORADAS DE LOS INICIOS DE EL ARGAR EN EL SURESTE PENINSULAR}

La ausencia de decoración de la cerámica se consideró desde el principio uno de los rasgos más definitorios del registro argárico (Siret y Siret 1890: 331; Siret 1913: 173, fig. 36). Solo P. Bosch Gimpera (1954: 49) apreció en las vasijas de Lugarico Viejo la representación de una fase de "transición" entre la cultura de Los Millares y la de El Argar. Durante décadas, los datos disponibles impidieron abundar en esta cuestión, dado

Figueras Pachecho, F. Excavaciones en la Isla de El Campello. Alicante. 1935. Memoria redactada por el Delegado Director, 1939. Ejemplar mecanográfico. Biblioteca Gabriel Miró. Fundación Caja Mediterráneo. Alicante.

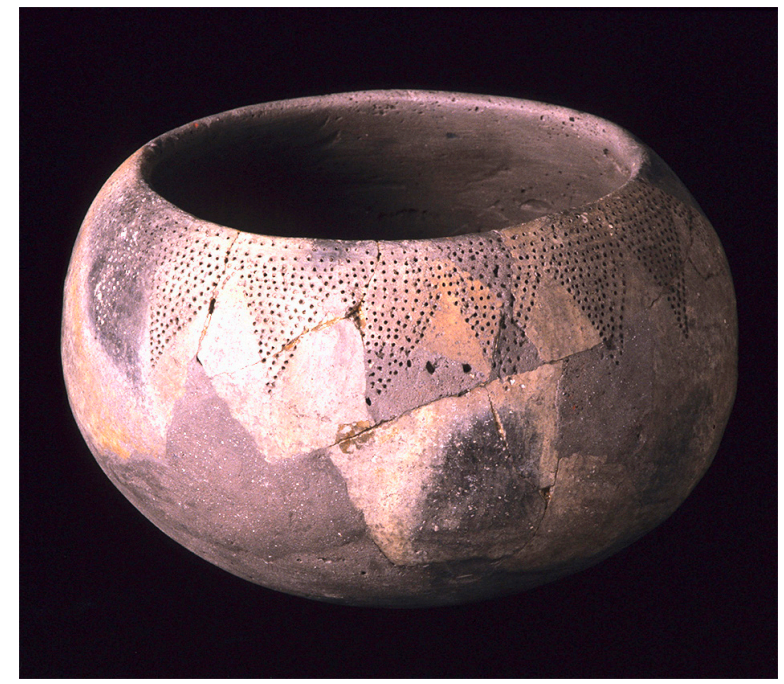

Fig. 5. Illeta dels Banyets (El Campello, Alicante): cuenco con decoración puntillada. Archivo Gráfico del MARQ-Museo Arqueológico de Alicante. En color en la edición electrónica.

que en su inmensa mayoría procedían de tumbas o carecían de contexto estratigráfico. H. Schubart (1975) estableció la serie evolutiva de la cerámica sepulcral argárica a partir de rasgos exclusivamente morfológicos, como la posición de la carena con relación a la altura total del recipiente, asumiendo una ausencia radical de decoración limitada, en todo caso, a motivos bruñidos en el interior de algunas copas y cuencos.

Las firmes convicciones de H. Schubart (1976) en la preeminencia de unas raíces culturales foráneas en el complejo contexto formativo de El Argar convertían la carencia de cualquier tipo de relaciones entre la alfarería argárica y la de finales del Calcolítico en un sólido refuerzo argumental. Además, por entonces comenzó a difundirse la información sobre los hallazgos en Cuesta del Negro (Schubart 1975: 90, n. 57) que más adelante permitieron a F. Molina González (1978) definir y sistematizar el denominado Bronce Tardío del sureste. Su amplio repertorio de cazuelas de carenas altas y bordes exvasados, decoradas con excisiones, puntillados y, especialmente, líneas con la técnica del punto y raya $-\mathrm{o}$ boquique- mostraba una ruptura clara con las tradiciones alfareras argáricas precedentes. En consecuencia, para H. Schubart (1975: 90, n. 56), los vasos decorados de Lugarico Viejo debían corresponder en todo caso a una "etapa precedente de la Edad del Bronce Tardía".

Solo algunos investigadores, como V. Lull Santiago (1983: 246), continuarían contemplando la posibilidad de situarlos en un momento "pre-argárico" o "argárico inicial". Sin embargo, terminó prevaleciendo la atribución de una cronología avanzada para todo tipo de ce-

Trab. Prehist., 78, N. ${ }^{\circ}$ 1, enero-junio 2021, pp. 86-103, ISSN: 0082-5638

https://doi.org/10.3989/tp.2021.12266 
rámicas decoradas con triángulos rellenos de puntillados, halladas en yacimientos argáricos (Gil-Mascarell 1981; Ros 1986; Simón 1988, 1997).

Ahora, la aparición de estas cerámicas decoradas en los niveles basales de la estratigrafía de Tabayá (Aspe), Laderas del Castillo (Callosa de Segura) e Illeta dels Banyets (El Campello) obliga a reconsiderar esta postura. Además, su presencia en otros yacimientos del sureste evidencia que, lejos de constituir una mera peculiaridad del registro argárico del sur de Alicante, deben considerarse parte del bagaje artefactual de los primeros estadios de desarrollo de El Argar.

En el yacimiento de Santa Catalina del Monte, en Verdolay (Ruiz 1998), se documentó una amplia secuencia de ocupación desde el Calcolítico hasta época ibérica. La fase II correspondería, según su excavadora, a un Calcolítico final con cerámica campaniforme incisa de estilo Ciempozuelos, siendo la fase III una "etapa transicional" del Calcolítico a El Argar. Entre los fragmentos decorados publicados destacamos tres. Dos tienen series de triángulos verticales, rellenos por líneas incisas horizontales, similares a los identificados en estratos de nivelación del edificio turriforme B2 de Laderas del Castillo, y, un tercero, líneas incisas oblicuas convergentes, que al parecer formarían un zigzag alrededor del cuello del vaso (Ruiz 1998: 102, fig. 26. 5-6).

M. M. Ros Sala (1986: 41, lám. 1) adscribió al Bronce Tardío una pieza de Las Cabezuelas (Totana) que, tras nuestra revisión, encuadramos ahora, en cambio, en la fase inicial de El Argar (Fig. 6.1). El recipiente, con galbo de curva pronunciada sin llegar a marcar una carena, está decorado con dos series de triángulos invertidos rellenos de puntos. La primera, con los triángulos de mayor tamaño, decora el cuello y la otra la parte más ancha del cuerpo. Su similitud con el gran vaso decorado de Tabayá o con la vasija carenada de Lugarico Viejo resulta evidente. Existe, sin embargo, un problema en cuanto a su contextualización. Los fragmentos forman parte de un depósito realizado en el Museo Arqueológico de Murcia por Jorge Aragoneses en la década de 1970, proveniente de "Las Cabezuelas". No obstante, según las recientes excavaciones, la secuencia de ocupación del yacimiento hoy conocido como Las Cabezuelas no se remonta más allá de finales de la Edad del Bronce (Carricondo et al. 2018). Debemos deducir entonces que, o bien se hallaron en otro punto, hoy desaparecido, o bien -lo que consideramos más probable- la pieza se encontró realmente en otro lugar. En este sentido merece la pena recordar que en Totana también se conoce como "Las Cabezuelas" el paraje donde se ubica el yacimiento argárico de la Cabeza Gorda (Ayala y Tudela 1993).

Sin salir del término municipal de Totana, las excavaciones que se vienen efectuando desde 2008 en el yacimiento de La Bastida han permitido documentar,
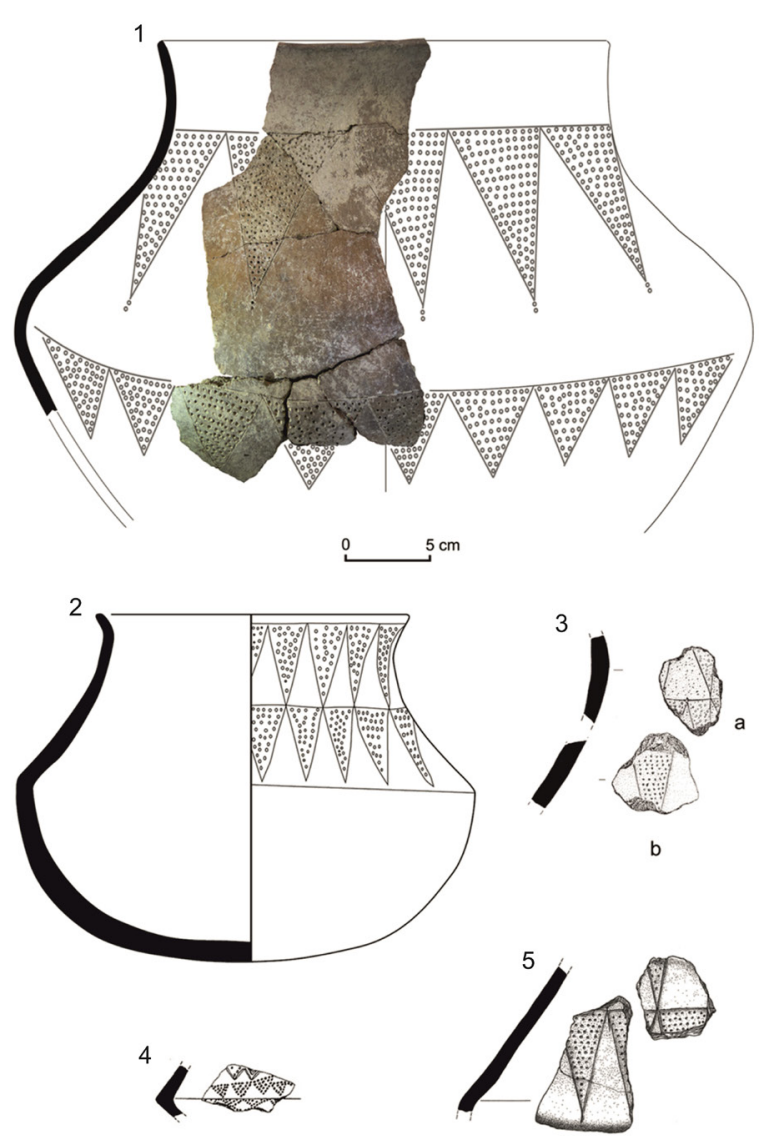

Fig. 6. Cerámicas decoradas con incisiones y puntillado de Murcia: 1. Las Cabezuelas (Totana, Murcia) y Almería: 2. Lugarico Viejo (Antas) (Schubart y Ulreich 1991: taf. 124.2); 3. Gatas (Turre) (adaptado de Castro et al. 1999: Anexo 1); 4. Fuente Álamo (Cuevas de Almanzora) (Schubart 2004: 73, fig. 10); 5: El Argar (Antas) (Schubart 2014: 66, Abb. 33.12). En color en la edición electrónica.

aunque considerablemente afectado por las fases posteriores, un nivel fundacional del asentamiento (Lull et al. 2015a: 377-378, fig. 9). Su repertorio cerámico se compone principalmente de cuencos y ollas con el borde indicado, así como algunas formas carenadas e incluso grandes tinajas de almacenamiento que anticipan el clásico modelo del pithos argárico. Recientemente, se ha reportado también la presencia de algunos fragmentos con decoraciones incisas, con motivos en forma de líneas y zigzags con técnica de puntillado, en los niveles fundacionales de la fortificación (Lull et al. 2018: 321, fig. 7).

Las vasijas localizadas en Lugarico Viejo por los Siret se hallaron en el interior de la casa A del poblado, de la que dibujaron un plano detallado (Siret y Siret 1890: 97-98, láms. 15 y 16). El cuenco decorado con 
líneas curvas incisas y puntillado se localizó cerca del extremo suroccidental de la estancia, y aproximadamente en el centro el recipiente carenado con cuello y borde saliente, decorado con dos series de triángulos invertidos encadenados, rellenos de puntillado (Fig. 6.2). Un tercer fragmento perteneciente a otra vasija similar no se señala en el plano (Siret y Siret 1890: lám. 16. o, p y x). Se ha publicado una datación radiocarbónica MAMS-15498: $3731 \pm 20 \mathrm{BP}-$ de este mismo contexto (Lull et al. 2015a: 381, Ap. 2) que sitúa el conjunto en torno a $2100 \mathrm{cal} \mathrm{BC}$.

Del yacimiento de Gatas solo se han divulgado en detalle hasta ahora los resultados de los sondeos realizados entre 1986 y 1989 (Castro Martínez et al.1999). Un fragmento de galbo, hallado en el subconjunto $7 \mathrm{~A} 1$ del Sondeo 1-G-S1-627-, repite el patrón decorativo, ya conocido, de dos series horizontales de triángulos invertidos encadenados rellenos de decoración puntillada (Fig. 6.3.a). Este subconjunto se incluye en la Fase IV, contando con una datación radiocarbónica KIK-63 / UtC-1443: 3420+/-110 BP- obtenida a partir de una muestra de madera (Castro et al. 1999: 82), que lo sitúa cronológicamente en torno a 1700 cal BC. Un fragmento similar al anterior-G-S3-710- conserva la parte central de un triángulo invertido relleno de puntillado, delimitado por líneas incisas (Fig. 6.3.b). Procede del sondeo 3 , y fue registrado entre los materiales del subconjunto 18 B1, también incluido en la Fase IV, plenamente argárica. Esta datación resulta claramente inconsistente con la cronología antigua que sugiere este tipo de piezas decoradas, y lo más probable es que se incluyeran como material de relleno proveniente de estratos inferiores.

Algo similar debe suceder con el fragmento de vaso carenado decorado adscrito al Horizonte III de Fuente Álamo (Schubart 2004: 73, fig. 10), que el propio autor relacionó con otra vasija de la forma 5 hallada en 1991 en El Argar (Schubart 2014: 75). El fragmento en cuestión (Fig. 6.4) muestra tres filas de pequeños triángulos invertidos, trazados en puntillado, de los que solo los de la parte superior tienen su contorno delimitado por líneas incisas.

Durante las excavaciones realizadas en 1991 en el yacimiento de El Argar se localizaron, en el estrato 2a del Sondeo 1, correspondiente con su fase inicial de ocupación, dos fragmentos de un vaso carenado con la característica decoración a base de triángulos invertidos rellenos de puntillado (Fig. 6.5) con un diámetro máximo estimado de $37 \mathrm{~cm}$ (Schubart 2014: 73, Abb. 33.12). La intensidad de la ocupación posterior de época medieval posiblemente explica el resultado de la datación radiocarbónica-UGAMS 16147: $3240 \pm 30$ BP (1611-1439 cal BC) - obtenida para el estrato basal infrapuesto al estrato 2a, y que se sitúa muy lejos de las fechas que cabría esperar para este momento (Schubart et al. 2014: 104, tab. 4-6).

Atendiendo a estos nuevos datos merece la pena reconsiderar una antigua noticia. Nos referimos al vaso decorado hallado en la sepultura 942 de El Argar, mencionado por los Siret (1890: 153) precisamente para destacar su excepcionalidad entre la vajilla funeraria del yacimiento. Aunque Luis Siret nunca se extendió en detalles, según las notas del cuaderno de campo de Pedro Flores se trataba de "una puchera parecida a la de la casa del Lugarico Viejo". De acuerdo con la documentación conservada, la tumba 942 era una cista de lajas en cuyo interior se depositó un individuo acompañado de un vaso carenado, uno de la forma 8 y un fragmento de cuenco, junto a un cuchillo o puñal y un punzón metálicos y un hueso de animal (Schubart y Ulreich 1991: 173). El croquis que acompaña a la sucinta descripción de P. Flores en su cuaderno nos ofrece datos adicionales, como que el cuenco se encontró dentro del vaso carenado, así como un esbozo de su decoración (Fig. 7). La vasija carenada es la única pieza del ajuar que se ha conservado. Está decorada en su parte superior con cuatro paneles aproximadamente cuadrangulares, de desigual tamaño, realizados con un puntillado grueso, y se identifica entre los materiales conservados en los Musées Royaux d'Art et d'Histoire de Bruselas incluidos por H. Schubart y H. Ulreich (1991: 293, taf. 137. 130) entre el material de procedencia desconocida.

\section{DISCUSIÓN}

Uno de los rasgos distintivos señalados recurrentemente en relación con la identificación de El Argar ha sido la singularidad y normalización de su cultura material. En la cerámica (Siret y Siret 1890; Cuadrado 1950; Lull 1983; Aranda 2004, entre otros) la total ausencia de decoración constituye uno de los elementos en los que de forma más unánime se ha reconocido "lo argárico", de modo que cualquier atisbo de esta ha sido tradicionalmente atribuido a cronologías posteriores (Molina González 1978; González 1994; Castro et al.1996; Aranda 2004).

Sin embargo, como hemos visto, en los niveles arqueológicos iniciales de un número significativo de asentamientos, distribuidos a lo largo y ancho de la fosa intrabética del sureste de la península ibérica, se constatan materiales cerámicos con decoraciones de líneas quebradas, zigzags, líneas paralelas de puntos y rayas y otros motivos incisos, entre los que predominan los triángulos invertidos rellenos de puntillado. Por el momento, su representación en el conjunto de la vajilla de esta fase inicial de El Argar solo puede estimarse a partir de los valores preliminares obtenidos

Trab. Prehist., 78, N. ${ }^{\circ}$ 1, enero-junio 2021, pp. 86-103, ISSN: 0082-5638

https://doi.org/10.3989/tp.2021.12266 

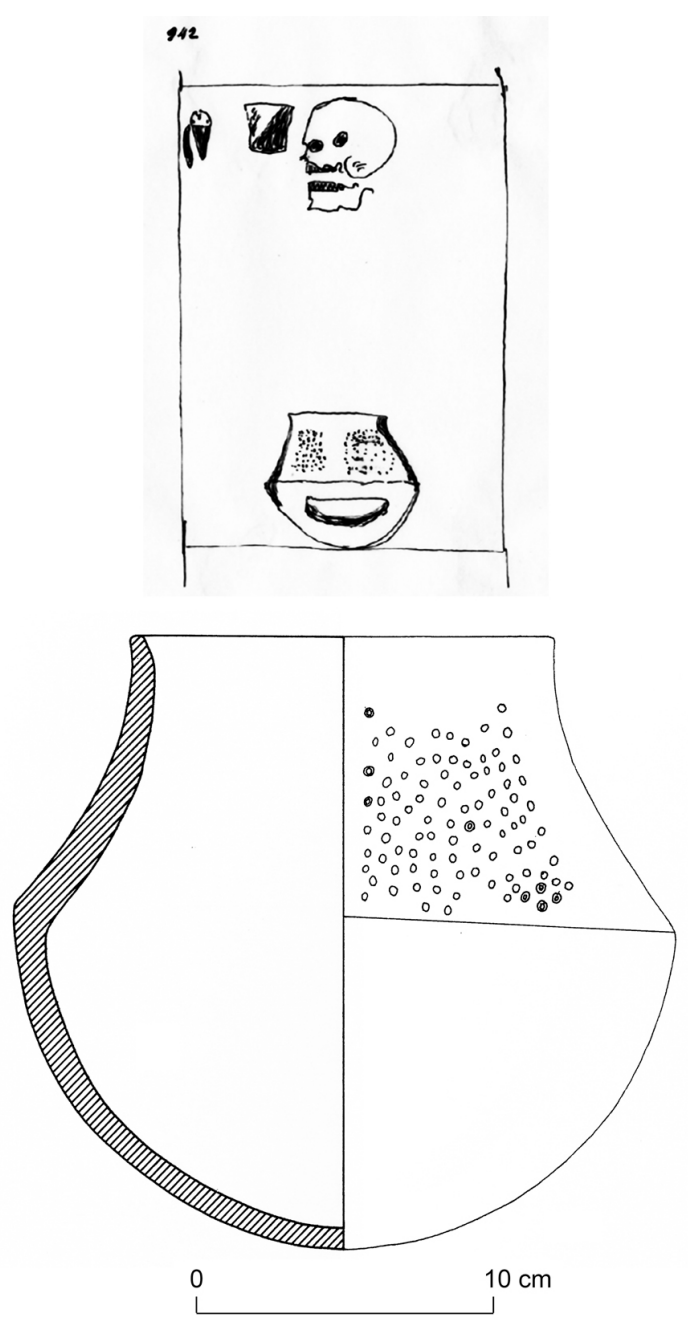

Fig. 7. Tumba 942 de El Argar: arriba, croquis del cuaderno de P. Flores (Documentación Siret. Museo Arqueológico Nacional. Red Digital de Colecciones de Museos de España); abajo, vasija cerámica con decoración incisa procedente de la tumba (Schubart y Ulreich, 1991: taf. 137.130).

en Laderas del Castillo: entre $0,37 \%$ y $3,33 \%$. Estos datos invitan a considerar un carácter singular para los recipientes decorados, similar al que se les atribuye en los momentos calcolíticos precedentes, donde sus proporciones son parecidas.

La explicación de este aspecto del registro ha de retomar necesariamente la idea, apuntada por P. Bosch Gimpera (1954: 49) y asumida y defendida por otros investigadores (Lull 1983: 246) que suponía estas decoraciones pervivencias de tradiciones alfareras del Calcolítico en una fase formativa de El Argar. Por tanto, como se señaló hace años a propósito de los hallazgos realizados en Tabayá (Hernández 1997: 107), la lógica empuja en principio a rastrear su origen en el Campaniforme inciso tardío.

El repertorio campaniforme ofrece multitud de patrones de líneas horizontales incisas, con series de triángulos invertidos rellenos de líneas o reticulados (Harrison 1977). En unas ocasiones aparecen como series horizontales de triángulos con bases y ápices opuestos alternos, formando en conjunto una banda más ancha, a menudo dispuesta alrededor del cuello de las vasijas, definiendo entre los triángulos un motivo en zigzag. En otras, las series de triángulos invertidos, más o menos alargados, arrancan de la zona más amplia del galbo decorando de forma radial la parte inferior del recipiente. Este último patrón es, por ejemplo, común en la vajilla de yacimientos del noreste de la península ibérica del complejo Salamó, y de otros muchos enclaves campaniformes tardíos, como el Promontori del Aigua Dolça i Salada, de Elche (Ramos 1984) o el Peñón de la Zorra, en Villena (Alba y García 2018).

En cambio, resultan muy raros los triángulos con el interior del campo relleno de puntillado (Harrison 1977: 131, fig. 56. 717; 232, fig. 107. 2034). Este suele limitarse al interior de bandas horizontales con una $\mathrm{o}$, con más frecuencia, dos o tres líneas de puntos en paralelo, y solo a veces forma otros motivos, como líneas en zigzag o círculos.

Por el contrario, en la etapa previa al campaniforme los triángulos invertidos con relleno de puntillado son relativamente numerosos. Los hay en cerámicas del asentamiento de Almizaraque (Fernández-Miranda et al. 1993: 79, fig. 16.1) y de necrópolis como Los Millares (Almagro y Arribas 1963: lám. CXIX; Martin y Camalich 1982: 290, fig. 2.a), en la provincia de Almería, pero también en asentamientos y cuevas de enterramiento del noroeste murciano, en la cueva de los Tiestos y en El Prado, en Jumilla (Molina Burguera 2003: 40, fig. 20. 172, 123) y, en la provincia de Alicante, en asentamientos del valle del Vinalopó, como La Torreta - El Monastil (Jover 2010: 140, fig. 113; 205, fig. 192) o La Macolla (Soler García 1981: 30, fig. 15) y cuevas de enterramiento del valle del Serpis, como la Cova del Balconet, en Cocentaina (Pascual 1988: 132, fig. 19.6).

Significativamente, también en la vajilla calcolítica precampaniforme encontramos precedentes a la decoración incisa a base de series de líneas curvas cóncavas, en forma de guirnalda (Martin y Camalich 1982), similares a las de los cuencos de Tabayá y Lugarico Viejo, un motivo muy poco frecuente -por no decir inexistente- entre el repertorio decorativo campaniforme.

La cuestión relevante en estos momentos es, pues, explicar la presencia de cerámicas campaniformes en la base de las estratigrafías de un significativo número de yacimientos argáricos distribuidos por la fosa intrabética (López 2006; Lull et al. 2010), y de un conjunto 
de cerámicas en las que predominan técnicas y motivos decorativos característicos de momentos precampaniformes. Esto nos enfrenta en realidad con una problemática general de la praxis arqueológica: la identificación del conjunto de los rasgos materiales de los periodos de rápida transformación social, expuestos a quedar vacíos de contenido debido a que sus atributos pueden adscribirse equivocadamente a las fases previas o subsiguientes, si están mejor definidas arqueográficamente.

Un primer paso hacia la superación de la lectura disociativa predominante entre la materialidad del bien definido "equipamiento campaniforme", y la no menos bien definida "norma argárica", ha sido la interpretación de los niveles basales de algunos yacimientos en las últimas décadas, una vez confirmado que contenían cerámicas decoradas. En general, los niveles se consideraron expresiones de un "Bronce local", puesto que no parecía razonable situarlos abiertamente en un Campaniforme Tardío o en un contexto argárico. Dos casos paradigmáticos son Tabayá (Aspe, Alicante) y el Cerro de la Virgen (Orce, Granada).

Tras identificarse inicialmente como "epicampaniforme" (Simón García 1998: 333), la fase inicial de la secuencia de Tabayá se atribuyó a un "Bronce Antiguo preargárico" (Hernández 2009: 166), optando incluso por términos aún más vagos (Barciela 2016: 577). Por su parte, Molina González y otros (2017: 261) en su reformulación de la periodización del Cerro de la Virgen situaron las fases III.1 y III.2 -que vendrían a corresponder a la fase IIIA de W. Schüle (1980)- dentro de un "Bronce Antiguo Final", siempre inmediatamente previo a los primeros niveles reconociblemente "argáricos". Resulta ahora complicado continuar sosteniendo este tipo de interpretaciones toda vez que, además del caso claro de Tabayá, una parte significativa del registro cerámico de ese "Bronce Antiguo preargárico" es compartido por un considerable número de asentamientos distribuidos, precisamente, por la geografía más antigua de El Argar.

Hace ya tiempo se indicaba que la distribución de cerámicas campaniformes a lo largo de las cuencas media y baja del Segura anticipaba el paisaje del poblamiento argárico posterior, evidenciando hasta dónde profundizaban las raíces del proceso que culminaría con la conformación del grupo argárico (López 2006: 230). Estas consideraciones concedían una necesaria antecedencia a las transformaciones y al cambio en las relaciones sociales de producción de una formación social, con respecto a la de la materialidad resultado de dichas transformaciones (Bate 1998; Patterson 2003). Aplicado al caso que aquí nos ocupa, implica que los primeros pasos hacia la configuración de 'lo argárico' debieron preceder al momento en que esta configuración empieza a ser reconocible en los parámetros ar- queográficos establecidos. Pero eso no excluye su temprano reflejo en el registro arqueológico.

En nuestra opinión, la ubicación de los asentamientos en el territorio es uno de los aspectos que más rápidamente revela transformaciones profundas en las relaciones sociales de producción. Ello se debe a que las variaciones en cuanto a la disponibilidad de tierra, el objeto de trabajo fundamental, es uno de los factores que exige una respuesta más rápida del grupo social ante cambios en las relaciones de propiedad. Precisamente en ese sentido se ha valorado el cambio de ubicación de ciertos emplazamientos del Bajo Segura en momentos avanzados del III milenio (López 2009: 258; Jover et al. 2019b: 1009, fig. 8).

El análisis de los mapas de visibilidad de algunos asentamientos campaniformes del Bajo Segura y Bajo Vinalopó - sin continuidad en su ocupación- y su comparación con los de otros fundados en sus proximidades -algunos a escasamente $500 \mathrm{~m}$ de distancia- muestra un cambio de estrategia de control visual. El interés claramente volcado sobre el cauce del río de los primeros se orientó a un control más extenso e intensivo de todo el territorio en los segundos. El hecho de que estos últimos sean los enclaves que, convertidos después en núcleos argáricos, prolongarán su ocupación durante la Edad del Bronce, hace pensar que debió responder a un nuevo plan de control y explotación del espacio, coordinado, planificado y dirigido políticamente, que anticipó, a finales del Calcolítico, la exitosa estrategia seguida después, durante más de medio milenio, por el grupo argárico. Los datos proporcionados por las recientes excavaciones en Laderas del Castillo y su valoración conjunta con los de las intervenciones realizadas a finales de los 1980 en Tabayá, permiten una nueva evaluación de este proceso, en el que intuimos tuvo que estar involucrada también una amplia zona oriental del sureste.

Una suma de evidencias apunta a que las construcciones de la fase inicial de la secuencia de Laderas del Castillo, en la zona excavada hasta ahora, desmantelaron un asentamiento anterior. En todo caso, la terraza inferior, en el Sector 3 excavado, así como el edificio turriforme B2 asociado, y la vivienda $\mathrm{C}$, levantada directamente sobre ella, presentan materiales y cronologías radiocarbónicas que nos sitúan en momentos finales del Calcolítico.

Los materiales documentados sobre los derrumbes de estas estructuras, asociados a la construcción del edificio turriforme $\mathrm{B} 1$, incluyen algunos fragmentos de cuencos con decoraciones de triángulos verticales, alargados, que penden de una línea incisa horizontal, rellenos de incisiones verticales unidas en el vértice del triángulo. También aparecen estas decoraciones en los estratos basales de Tabayá y en el nivel más reciente del Promontori de Aïgua Dolça i Salada (Elche, 
Alicante), en su día atribuido al "Bronce Valenciano" (Ramos 1984: fig. 9). Entre los estratos de derrumbe posteriores documentamos fragmentos decorados con zigzags de líneas incisas o con puntillado, o combinando series horizontales de triángulos o líneas quebradas con vértices opuestos alternos, conformando bandas también en zigzag.

Los primeros datos apuntan a una progresiva simplificación de los diseños decorativos a lo largo de la secuencia de Laderas del Castillo y de Tabayá. Los más barrocos aparecen por ahora en los estratos más antiguos. Son series consecutivas de triángulos, líneas perimetrales bien marcadas e incluso trazos verticales a modo de flecos (Fig. 4.3) o que añaden trazos incisos en el vértice de los triángulos (Fig. 2.2). En cambio, en niveles más recientes (Fig. 4.7) se documenta los recipientes con triángulos en puntillado sin contorno definido por líneas incisas. Un aspecto ligado más estrechamente con las tradiciones calcolíticas es la disposición de decoración bajo la línea de carena -Las Cabezuelas (Fig. 6.1)o en el cuerpo de la vasija-Tabayá (Fig. 2.1)- aunque no es posible precisar aún si este rasgo les otorga mayor antigüedad con respecto a los recipientes carenados de Lugarico Viejo, Gatas o El Argar, en los que las series de triángulos invertidos aparecen exclusivamente por arriba de la línea de carena.

Los motivos en zigzag situados en el cuello de algunas de las vasijas de Tabayá y Laderas del Castillo se repiten en los niveles fundacionales de la fortificación de La Bastida (Lull et al. 2018: 322, fig. 7) en fechas muy similares (Lull et al. 2015a: 398, Ap. 1). Una escueta versión del mismo motivo se observa en un fragmento hallado entre los rellenos de nivelación de una de las terrazas de Laderas del Castillo (Fig. 8.1). Pertenece a una vasija con cuello y borde ligeramente exvasado con dos líneas paralelas de puntos que describen un zigzag alrededor del cuello. Este estrato, compuesto por materiales en deposición secundaria, posee una datación radiocarbónica (Beta 510284: $3650 \pm 30$ BP) que fija una fecha ante quem entre 2050 y 1950 cal BC. La decoración en zigzag de este fragmento y su cronología parecen alinearse bien con la tendencia a la progresiva imposición de trazos exclusivamente en puntillado, prescindiendo de las líneas incisas, observada en los triángulos invertidos.

Por otro lado, sus estrechas analogías con uno de los vasos del Cerro de la Virgen (Schüle 1980: taf. 103, v.258) (Fig. 8.2) nos aboca necesariamente a otras consideraciones. Está incluido entre los materiales del nivel IIIB, pero su excavador ya señalaba que posiblemente proviniera de los estratos inferiores, removidos durante la excavación de las fosas de las sepulturas argáricas. La datación radiocarbónica de Laderas del Castillo aconseja ahora una cronología más bien en el intervalo 2100-2000 cal BC. Según la última propuesta
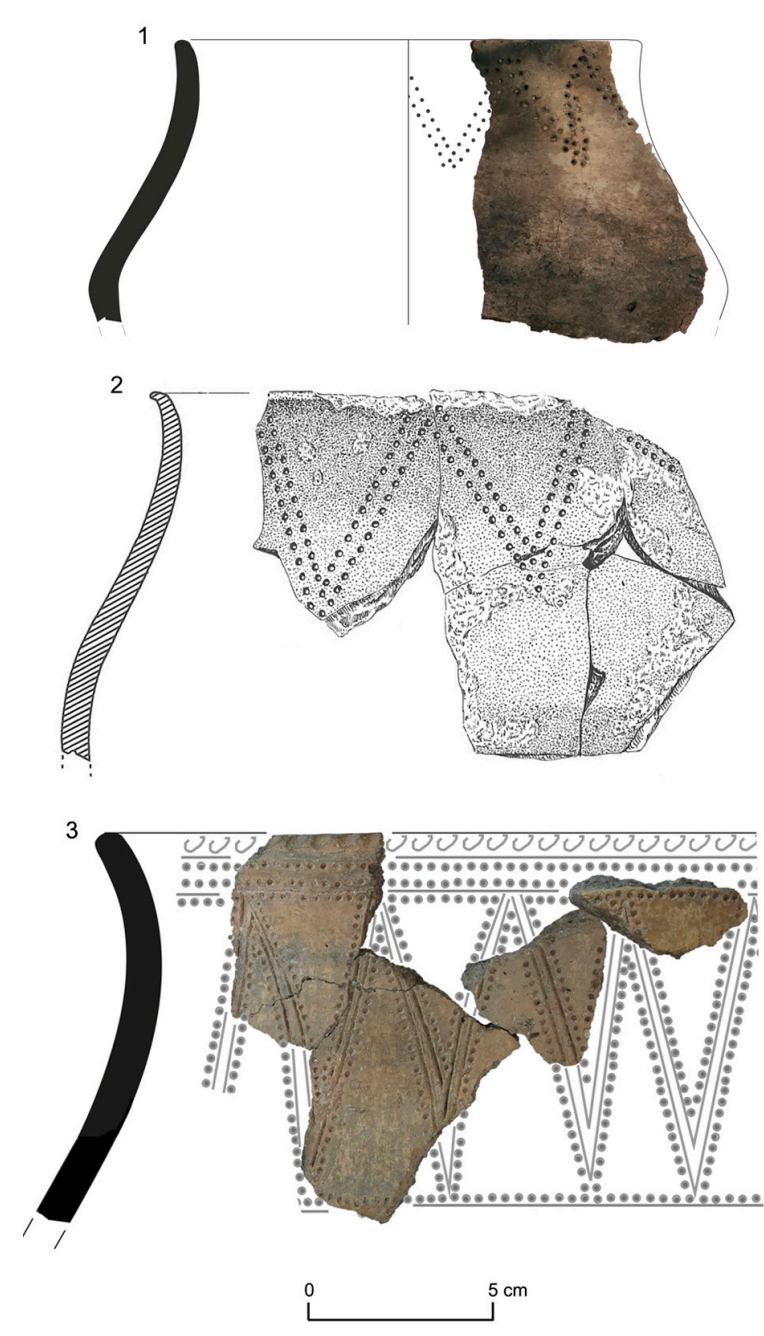

Fig. 8. Vasijas decoradas con incisión y puntillado con motivos en zig-zag: 1. Laderas de Castillo (Callosa de Segura, Alicante); 2. Cerro de la Virgen (Orce, Granada) (adaptado de Schüle 1980: taf. 103, v.258); 3. Tabayá (Aspe, Alicante). En color en la edición electrónica.

de periodización para el yacimiento granadino vendría a situarse, no obstante, en el denominado "Bronce local" preargárico, desafortunadamente no publicado aún en detalle. Ello impide precisar el significado del hallazgo de estas cerámicas en los extremos oriental y occidental del territorio más antiguo de El Argar, aunque indudablemente constituye un elemento más a considerar en el debate abierto en los últimos años acerca de la cronología del grupo argárico en el Cerro de la Virgen (Delgado-Raack 2013: 17, 121; Molina González et al. 2014: 124; Lull et al. 2015a: 387). 


\section{CONCLUSIONES}

A partir de la evidencia reunida, creemos incuestionable que las cerámicas con decoración incisa forman parte de la vajilla de la fase inicial de ocupación de un número considerable de asentamientos argáricos. Esta circunstancia, ya apuntada hace tiempo a propósito de los vasos decorados de Lugarico Viejo (Lull 1983: 246), se consolidó a raíz de su datación radiocarbónica (Lull et al. 2015a) y cobra ahora un considerable respaldo empírico. Otra cuestión distinta son las implicaciones que esto tiene en cuanto a la interpretación y explicación del proceso de conformación tanto de la sociedad argárica como del resto de entidades sociales concretas de su periferia.

La primera de estas implicaciones es de índole cronológica y se refiere a la probada ausencia de cerámicas con decoraciones similares -0 incluso con decoraciones de cualquier otro tipo- en los niveles fundacionales de los yacimientos contemporáneos excavados en esa periferia como El Acequión, Terlinques, Cabezo de la Escoba, Serra Grossa o la Lloma de Betxí, por ejemplo. Tal constatación confiere gran consistencia a la hipótesis de que se trata de un tipo de vajilla expresamente vinculada a las primeras fases de desarrollo de los yacimientos argáricos, y desligada por completo del registro asociado a la formación de otros grupos arqueológicos de su misma cronología. No menos destacable es su ausencia en aquellos enclaves argáricos fundados a partir de inicios del II milenio cal BC, como Cabezo Pardo, Caramoro I o Barranco de la Viuda, por citar solo algunos bien conocidos. Ello establece un intervalo 2200-2000 cal BC para la vigencia de estas formas y decoraciones cerámicas en la secuencia de El Argar.

En segundo lugar, cabe considerar la distribución que muestran estas cerámicas en el territorio del sureste de la península ibérica. En contra de lo que se ha venido sugiriendo hasta ahora (Arteaga 2000; Molina y Cámara 2004; Lull et al. 2010; 2015a) deberemos suponer que los yacimientos argáricos del Bajo Segura y Bajo Vinalopó, e incluso del Camp d'Alacant -cuyo punto de dispersión más septentrional es la Illeta dels Banyets- participan en la construcción del "área nuclear" argárica al igual que los enclaves del Almanzora, la cuenca de Vera y el valle del Guadalentín.

Desde nuestro punto de vista esto vendría, además, a otorgar mayor coherencia a la explicación del proceso de construcción del espacio social inicial argárico tanto desde el punto de vista fisiográfico como sociopolítico. Como muestra el mapa de la figura 9, con la inclusión del Bajo Segura y del Bajo Vinalopó ese espacio corresponde, con gran aproximación, a la denominada "depresión prelitorial murciana", una unidad geográfica bien definida, conformada principalmente por las cuencas del medio y bajo Guadalentín y la cuenca del bajo Segura, al este, y la cuenca de Vera y del bajo Almanzora, al oeste. De este modo, además, el núcleo argárico constituido en torno a las sierras de La Tercia y Espuña, donde se sitúan los enclaves de mayor tamaño, como Lorca y La Bastida de Totana, abandonarían la desconcertante posición excéntrica que guardaban con respecto al supuesto territorio "nuclear argárico" considerado hasta ahora, ocupando una centralidad más acorde con lo que permiten deducir los datos.

Los hallazgos descontextualizados de cerámicas campaniformes ya hacían pensar en una vinculación de los grupos de finales del Calcolítico con el origen del poblamiento argárico en el Bajo Segura y Bajo Vinalopó (Hernández 1986; López 2006). La estratigrafía de Laderas del Castillo ha permitido ahora no solo corroborarla, en su caso, sino también proporcionar más y mejores evidencias relacionadas con este proceso. La ocupación inicial del yacimiento puede atribuirse a momentos finales del Calcolítico, pero no es menos cierto que en determinados aspectos anticipa características estrechamente ligadas a El Argar. Entre ellas están la disposición del asentamiento en ladera, con viviendas de planta alargada y extremos curvos, organizadas sobre grandes terrazas en las cuales, adosadas o parcialmente embebidas en su paramento, encontramos edificaciones de aspecto turriforme, de planta aproximadamente cuadrangular. La secuencia del yacimiento no muestra, por otra parte, evidencia ninguna de discontinuidad en la ocupación tras la destrucción de las viviendas de esta primera fase. Entre sus derrumbes y los niveles correspondientes a los edificios que arqueográficamente podríamos ya considerar claramente argáricos localizamos la mayor parte de las cerámicas con decoraciones incisas y con puntillado. Constituyen, no obstante, un porcentaje muy reducido del material cerámico. Junto a estas se documentan otros elementos tan ligados al registro arqueológico calcolítico como ellas, pero de los que, en cambio, nunca se cuestionó su pertenencia a los primeros contextos argáricos, sin duda por su más larga pervivencia en ellos. Es el caso de los botones piramidales de perforación en $\mathrm{V}$, de las puntas lanceoladas de metal, o de las placas líticas perforadas denominadas "brazales de arquero" (Schubart 1975: 91, fig. 6).

Hasta donde la secuencia de Laderas del Castillo nos ha permitido registrar, los últimos tipos cerámicos con decoración documentados se datan en torno a 2000 cal BC, y consisten básicamente en cuencos con motivos triangulares, con el vértice invertido, dispuestos en serie a lo largo del borde externo. Estos triángulos carecen ya de contorno definido por líneas incisas, y se realizan exclusivamente con un puntillado más o menos profuso. Algunos tienen relleno de un material de color blanquecino, como muestra algún fragmento 
hallado en la Illeta dels Banyets, una técnica, por lo demás, ampliamente extendida ya a finales del Calcolítico (Odriozola 2019).

Quedan cuestiones que no es posible resolver por el momento, como explicar por qué el repertorio decorativo de estas cerámicas sugiere vínculos más estrechos con la vajilla decorada precampaniforme, de uso extendido por una amplia zona del cuadrante sudoriental de la península ibérica durante la primera mitad del III milenio $\mathrm{BC}$, que con los motivos más típicos del Campaniforme inciso, más cercanos en el tiempo. O también, si el predominio de la decoración en recipientes carenados que se aprecia en el área de la cuenca de Vera y del Almanzora, frente al de cuencos y ollas de borde exvasado en el Bajo Segura y Bajo Vinalopó, se debe a algo más que al mero azar en la composición de un registro que apenas comenzamos a construir.

En cualquier caso, el recipiente carenado localizado en la sepultura 942 de El Argar constituye, a nuestro juicio, una pieza fundamental que permite conectar el final de la tradición decorativa de la fase inicial de El Argar con uno de los elementos básicos de la es- tructura identitaria argárica, como es la inhumación individual en el interior del área habitada. La más que sucinta descripción de Flores conservada basta para descartar cualquier atisbo de duda acerca de su argarismo. Actualmente no es posible atribuir una cronología radiocarbónica a la sepultura debido a que no se han conservado restos orgánicos, pero ninguno de los elementos de los que se compone desentona con los de otras tumbas similares en cista de lajas con elevadas dataciones radiocarbónicas, como la T-42 de Gatas (Lull et al. 2015a: 387).

Las fechas obtenidas en el edificio A de Laderas del Castillo (López et al. 2018), marcan un horizonte cronológico de 2000-1950 cal BC para la definitiva desaparición de estas decoraciones, que ya no vuelven a registrarse en la estratigrafía del yacimiento. Esta desaparición, coincidente con la imposición de los “cánones" argáricos en la morfología de la vajilla, resulta así mismo contemporánea a la de una serie de profundas transformaciones sociales que afectaron de forma decisiva a todo el territorio de El Argar. Estas son la consolidación un nuevo espacio social con unas nue-

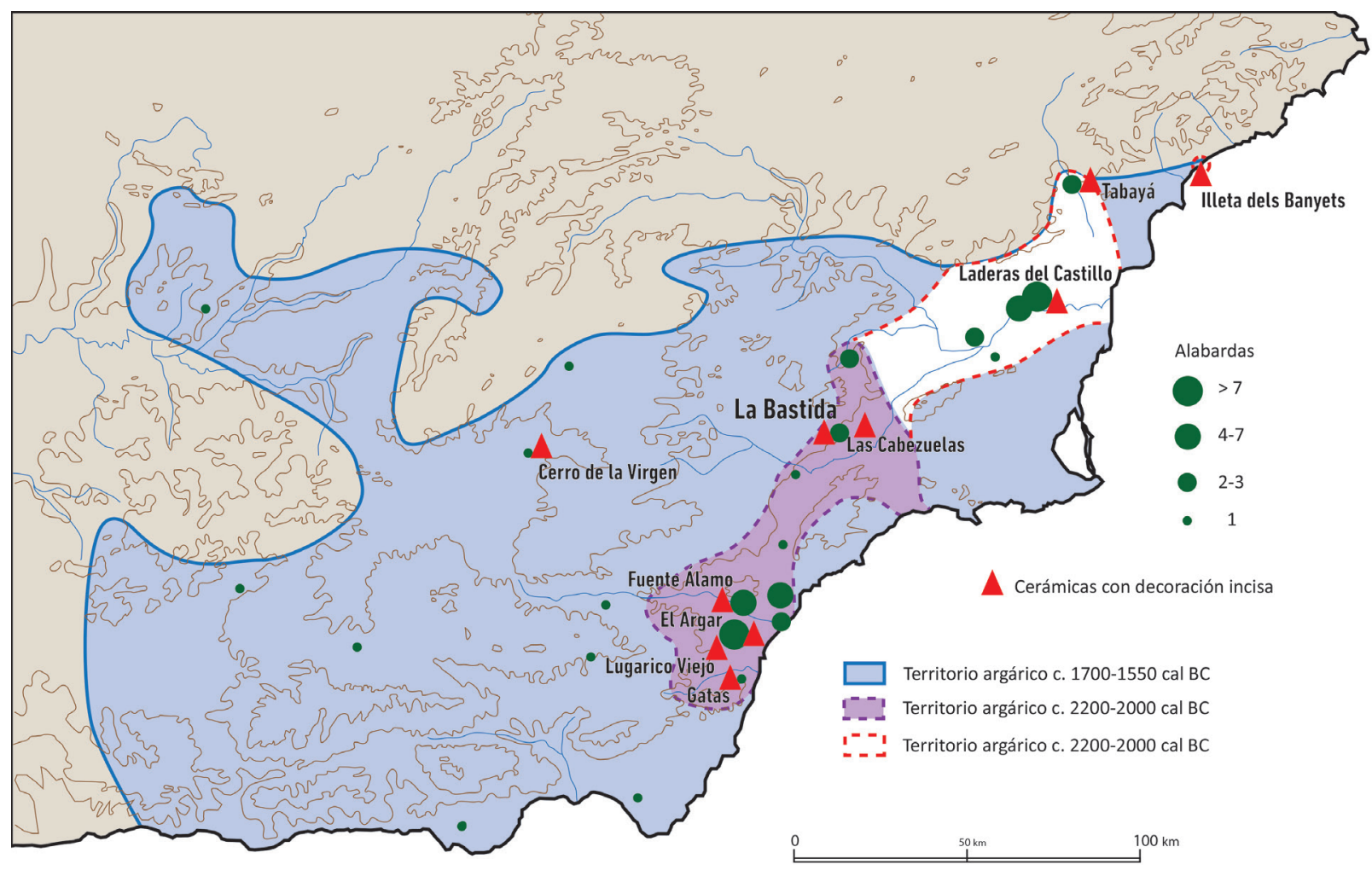

Fig. 9. La máxima expansión del grupo argárico (línea continua y tono más claro) y el territorio considerado hasta ahora "nuclear" (línea discontinua y tono más oscuro) (Lull et al. 2015: 373, fig. 5) en el cuadrante sudoriental de la península ibérica. En línea discontinua y color blanco, la ampliación incluida por nosotros. El tamaño de los círculos se corresponde con el número de alabardas de metal (Lull et al. 2017: 149, fig. 2). El triángulo localiza los yacimientos con cerámicas incisas y puntillado de 2200-2000 cal BC. En color en la edición electrónica. 
vas relaciones sociales más jerárquicas, manifestadas en la fundación de nuevos asentamientos, planificada y dirigida desde los centros políticos y orientada tanto al incremento global de la producción agropecuaria como al control efectivo del territorio (López y Jover 2014: 396; Jover et al. 2019b: 1020); y la institucionalización de la herencia de los derechos de propiedad, manifestada por los primeros enterramientos infantiles constatados en los asentamientos (Lull et al. 2005: 253).

Desde nuestro punto de vista la supresión de cualquier tipo de ornato en la cerámica y la imposición de un lenguaje único en la producción alfarera pueden ser leídos como consecuencia de la culminación de un proceso de cohesión y consolidación grupal. En el caso del grupo argárico, algunos otros aspectos del registro indican que este proceso conllevó además el surgimiento de una sociedad clasista inicial (Bate 1984; Jover 1999) cuya conformación no se alcanzó al margen de un profundo conflicto social. De acuerdo con los estudios más recientes, la cronología del arma de combate argárica por antonomasia, la alabarda metálica, se remonta precisamente al horizonte cronológico del 2000 cal BC (Lull et al. 2017: 150, fig. 3), y su distribución indica que, si bien acompañó a la sociedad argárica en su expansión hacia occidente, la máxima concentración de efectivos se da, precisamente, en el ámbito de la depresión prelitoral murciana (Lull et al. 2017: 149, fig. 2). Cabe suponer, pues, que este ámbito constituyó el epicentro del cambio social (Fig. 9) y que, desde este momento, deberemos considerarlo en su conjunto como el escenario de la construcción de El Argar como una sociedad histórica concreta. Otra cuestión diferente sería determinar en qué punto concreto de ese espacio social pudo iniciarse dicha construcción que, por otro lado, creemos debió desarrollarse con una mayor rapidez de la que por ahora es posible advertir en el registro.

La intensa investigación de las dos últimas décadas ha puesto de relieve la extraordinaria complejidad de los cambios sociales involucrados en la conformación de la sociedad argárica. Su concurrencia en el tiempo con una diversidad de sociedades (Aunjetitz y Wessex, entre otras), con las que se considera "inaugurada" la Edad del Bronce en Europa difícilmente puede explicarse hoy como un hecho meramente azaroso. A nuestro juicio, esta circunstancia viene a reflejar las verdaderas dimensiones y calado de la compleja red de relaciones intersociales entretejida por las comunidades calcolíticas precedentes, cuyo colapso tuvo consecuencias al unísono en una amplísima parte del continente europeo. Los diversos y novedosos análisis -entre ellos, los relativos a la secuenciación del ADN nuclear- que se están llevando a cabo contribuirán, sin duda, a corto y medio plazo, a revelar aspectos que hasta ahora habían pasado inadvertidos. Sin embargo, las condiciones ma- teriales y el modelo de relaciones sociales existentes en las comunidades calcolíticas tuvieron que desempeñar un papel no menos protagonista que el de las sinergias y procesos ligados al derrumbe de la red de relaciones intersociales precedente, en la construcción de las nuevas entidades sociales de la Edad del Bronce que les sucedieron.

\section{AGRADECIMIENTOS}

Agradecemos a los revisores de la revista Trabajos de Prehistoria todas sus sugerencias y aportaciones, que han servido para enriquecer y mejorar el texto.

\section{BIBLIOGRAFÍA}

Åberg, N. 1921: La civilisation énéolithique dans la Péninsule Ibérique. A.-b. Akademiska bokhandeln i kommission. Uppsala.

Alarcón García, E. 2010: Continuidad y cambio social. Las actividades de mantenimiento en el poblado argárico de Peñalosa (Baños de la Encina, Jaén). Tesis de la Universidad de Granada. Granada. http://hdl.handle.net/10481/5670

Alba Luzón, M. y García Atiénzar, G. 2018: "Beaker pottery in the Peñón de la Zorra (Alicante, Spain): Change and emergence of social complexity between the Neolithic and the BronzeAge". Journal of Neolithic Archaeology 20: 59-76 https://doi.org/10.12766/jna.2018S.4

Almagro Basch, M. y Arribas Palau, A. 1963: El poblado y la necrópolis megalíticos de Los Millares (Santa Fe de Mondújar, Almería). Bibliotheca Praehistorica Hispana III, CSIC. Madrid.

Aranda Jiménez, G. 2004: "Craft specialization in pottery production during the Bronze Age in south-eastern Iberia”. Journal of Iberian Archaeology 6: 157-179.

Aranda Jiménez, G.; Montón-Subías, S. y Sánchez Romero, M. 2015: The archaeology of Bronze Age Iberia. Argaric societies. Routledge. Nueva York.

Arribas Palau, A. 1976: "Las bases actuales para el estudio del Eneolítico y la Edad del Bronce en el Sudeste". Cuadernos de Prehistoria y Arqueología de la Universidad de Granada 1: 139-156.

Arteaga Matute, O. 1993: "Tribalización, jerarquización y estado en el territorio del El Argar". SPAL 1: 179-208. https://doi.org/10.12795/spal.1992.11.09

Arteaga Matute, O. 2000: "La sociedad clasista inicial y el origen del estado en el territorio de El Argar". Revista Atlántico-Mediterránea de Prehistoria y Arqueología Social 3: 121-219.

Arteaga Matute, O. y Schubart, H. 1980: "Fuente Álamo. Excavaciones de 1977'. Noticiario Arqueológico Hispánico 9: 245-289.

Ayala Juan, M. M. y Tudela Serrano, M. L. 1993: "Espada del poblado argárico de 'La Cabeza Gorda o Cabezo de la Cruz' Totana (Murcia)". Verdolay 5: 17-23.

Barciela González, V. 2016: El lenguaje de los adornos. tecnología, uso y función. Adornos personales de la Edad del Bronce en Alicante y Albacete. Tesis doctorales, Universidad de Alicante. http://hdl.handle.net/10045/53182

Bate Petersen, L. P. 1984: "Hipótesis sobre la sociedad clasista inicial". Boletín de Antropología Americana 9: 5-29.

Bate Petersen, L. P. 1998: El proceso de investigación en arqueología. Crítica. Barcelona.

Belmonte Mas, D. y López Padilla, J. A. 2006: "Productos, desechos y áreas de actividad en la Illeta dels Banyets de El Campello (ca. 1900- ca. 1400 ANE): Actuaciones de 2000-2001". En J. A. Soler Díaz (ed.), La ocupación prehistórica de la Illeta dels Banyets (El Campello, Alicante), Serie Mayor 5. MARQ. Alicante: 173-208. 
Blance, B. 1964: "The Argaric Bronze Age in Iberia". Revista de Guimaraes 74 (1-2): 129-142.

Blance, B. 1971: Die Anfänge der Metallurgie auf der Iberischen Halbinsel. Studien zu den Anfängen der Metallurgie IV, Gebrüder Mann Verlag. Berlin.

Bosch Gimpera, P. 1920: "La Arqueología prerromana Hispánica”. En A. Schulten. Hispania (Geografía, Etnología, Historia). Tipografía La Académica de Serra y Russell. Barcelona: 133-205.

Bosch Gimpera, P. 1932: Etnologia de la Península Ibèrica. Alpha. Barcelona.

Bosch Gimpera, P. 1954: "La Edad del Bronce en la Península Ibérica". Archivo Español de Arqueología XXVII, 89-90: 45-92.

Carricondo Gázquez, V.; González Guerao, J. A. y Ramírez Águila, J. A. 2018: "Las Cabezuelas de Totana. Páginas de historia". XXIV Jornadas de Patrimonio Cultural de la Región de Murcia (Murcia 2018): 331-337. [Murcia].

Castro Martínez P. V.; Chapman, R.; Gili Suriñach, S.; Lull Santiago, V.; Micó Pérez, R.; Rihuete Herrada, C.... y Sanahuja Yll, M. E. 1999: Proyecto Gatas. 2. La dinámica arqueoecológica de la ocupación prehistórica. Consejería de Cultura. Junta de Andalucía. Sevilla.

Castro Martínez, P. V.; Lull Santiago, V. y Micó Pérez, R. 1996: Cronología de la Prehistoria Reciente de la Península Ibérica y Baleares (c. 2800-900 cal ANE). British Archaeological Reports International Series 652, BAR Publishing. Oxford.

Chapman, R. 1991: La formación de las sociedades complejas. El sureste de la península ibérica en el marco del Mediterráneo occidental. Crítica. Barcelona.

Colominas i Roca, J. 1931: "La Necrópolis de 'Las Laderas del Casti1lo' (Callosa de Segura, Provincia d'Alacant)". Anuari de l'Institut d'Estudis Catalans VIII: 33-39.

Contreras Cortés, F. (ed.) 2000: Proyecto Peñalosa: análisis histórico de las comunidades de la Edad del Bronce del piedemonte meridional de Sierra Morena y depresión de Linares-Bailén, Junta de Andalucía, Consejería de Cultura. Sevilla.

Contreras Cortés, F.; Moreno Onorato, A.; Arboledas Martínez, L.; Alarcón García, E.; Mora González, A.; Padilla Fernández, J. J. y García García, A. 2014: "Un poblado de la Edad del Bronce que tiene mucho que decir, Peñalosa: últimas novedades en la acrópolis oriental". Cuadernos de Prehistoria y Arqueología de la Universidad de Granada 24: $347-390$.

Cuadrado Díaz, E. 1947: "La expansión de la cultura de El Argar a través de Murcia". Crónica del III Congreso Arqueológico del Sudeste Español (Murcia 1947) y Boletín Arqueológico del Sudeste Español (B.A.S.E.) 8-11: 66-72.

Cuadrado Díaz, E. 1950: "Útiles y armas de El Argar. Ensayo de tipología”. I Congreso Nacional de Arqueología (Almería 1949): 103-125. Cartagena.

Déchelette, J. 1910: Manuel d'archéologie préhistorique, celtique et gallo-romaine II, Archéologie celtique ou protohistorique. Première partie: Age du Bronze. Librairie Alphonse Picard et Fils. Paris.

Delgado-Raack, S. 2013: Tecnotipología y distribución espacial del material macrolitico del Cerro de la Virgen de Orce (Granada). Campañas de 1963-1970: una aproximación paleoeconómica, British Archaeological Reports International Series 2518, BAR Publishing. Oxford.

Evans, J. 1958: "Two phases of prehistoric settlement in Western Mediterranean”. Annual Report. Institute of Archaeology 12: 49-70.

Fernández-Miranda, M.; Fernández-Posse, M. D.; Gilman, A. y Martín, C. 1993: "El sustrato neolítico en la Cuenca de Vera (Almería)". Trabajos de Prehistoria 50: 57-85.

https://doi.org/10.3989/tp.1993.v50.i0.489

Ferrer García, C. 2010: "El medio físico de la Vega Baja y el litoral de Guardamar: la génesis cultural de un paisaje" Guardamar del Segura, arqueología y museo [catálogo exposición]. MARQ-Museo Arqueológico de Alicante. Diputación de Alicante: 32-45.

Figueras Pacheco, F. 1934: Excavaciones en la Isla del Campello (Alicante) 1931-1933. Junta Superior del Tesoro Artístico 132, 7 (1933). Madrid.

Figueras Pacheco, F. 1950: "La isleta del Campello del Litoral de Alicante. Un yacimiento síntesis de las antiguas culturas del mediterráneo". Archivo Español de Arqueología 23: 13-37.
Flores, J. A. 2007: “La 'sociedad concreta' como contenido esencial del espacio social”. Boletín de Antropología Americana 43: 5-60. http://www.jstor.com/stable/40978262

Furgús, J. 1937: Col-lecció de Treballs del P. Furgús sobre Prehistòria Valenciana. Treballs Solts del Servei d'Investigació Prehistòrica 5. Valencia.

Gil-Mascarell Boscà, M. 1981: "Bronce Tardío y Bronce Final en el País Valenciano". En C. Aranegui y M. Gil-Mascarell y (eds.): El Bronce Final y el comienzo de la Edad del Hierro en el País Valenciano. Monografías del Laboratorio de Arqueología de Valencia 1. Valencia: 9-39.

Gilman, A. 1987: "El análisis de clase en la Prehistoria del Sureste". Trabajos de Prehistoria 44 (1): 27-34.

González Marcén, P. 1994: “Cronología del grupo argárico". Revista d'Arqueologia de Ponent 4: 7-46.

Harrison, R. J. 1977: The Bell Beaker cultures of Spain and Portugal. American School of Prehistoric Research, Peabody Museum. Harvard University, Bull. 35. Cambridge, Massachusetts.

Hernández Pérez, M. S. 1986: "La cultura de El Argar en Alicante. Relaciones temporales y espaciales en el mundo del Bronce Valenciano". Actas del Congreso 'Homenaje a Luis Siret'(1934-1984). Cuevas de Almanzora (1984): 341-350. Sevilla.

Hernández Pérez, M. S. 1997: "Desde la periferia de El Argar. La Edad del Bronce en las tierras meridionales valencianas". Saguntum 30: 93-114.

Hernández Pérez, M. S. 2009: “Entre el Medio y Bajo Vinalopó (Aspe, Alicante) 1987-1991”. En M. S. Hernández Pérez, J. Soler Díaz y J. A. López Padilla (ed.): En los confines del Argar: una cultura de la Edad del Bronce en Alicante en el centenario de Julio Furgús [catálogo exposición]. $M A R Q$-Museo Arqueológico Provincial de Alicante, Diputación Provincial. Alicante: 160-169.

Hernández Pérez, M. S.; López Padilla, J. A. y Jover Maestre, F. J. 2019: "Estratigrafía y radiocarbono: la tumba 1 y la cronología de la ocupación argárica del Tabayá (Aspe, Alicante)". Spal 28.1: 35-55. https://doi.org/10.12795/spal.2019.i28.02

Jover Maestre, F. J. 1999: Una nueva lectura del "Bronce Valenciano". Secretariado de Publicaciones. Universidad de Alicante. Alicante.

Jover Maestre, F. J. (ed.) 2010: La Torreta-El Monastil (Elda, Alicante). Del IV al III milenio AC en la cuenca del río Vinalopó. Excavaciones Arqueológicas. Memorias 5, MARQ-Museo Arqueológico Provincial de Alicante. Alicante.

Jover Maestre, F. J. y López Padilla, J. A. 1997: Arqueología de la muerte. Prácticas funerarias en los límites de El Argar. Universidad de Alicante, Secretariado de Publicaciones. Alicante.

Jover Maestre, F. J.; López Padilla, J. A. y García Atiénzar, G. 2019b: "Territory, settlements, and households: Chalcolithic and Bronze Age in the eastern Iberian Peninsula". En H. Meller, S. Friederich, M. Küsner, H. Stäuble and R. Risch (eds.): Late Neolithic and Early Bronze Age Settlement Archaeology. 11 ${ }^{\text {th }}$ Archaeological Conference of Central Germany (Halle, Saale 2018). Tagungen des Landesmuseums für Vorgeschichte Halle 20, 2, Landesamt für Denkmalpflege und Archäologie Sachsen-Anhalt, Landesmuseum für Vorgeschichte. Halle (Saale): 1003-1027.

Jover Maestre, F. J.; Pastor Quiles, M.; Basso Rial, R.; Martínez Monleón, S. y López Padilla, J. A. 2019a: "Secuencia de ocupación y desarrollo constructivo del asentamiento de Caramoro I (Elche, Alicante): aportaciones a la arquitectura argárica". Arqueología de la Arquitectura 16: e083. https://doi.org/10.3989/arq.arqt.2019.005

Knipper, C.; Rihuete-Herrada, C.; Voltás, J.; Held, P.; Lull Santiago, V.; Micó Pérez, R.... y Alt, K. W. 2020: "Reconstructing Bronze Age diets and farming strategies at the early Bronze Age sites of La Bastida and Gatas (southeast Iberia) using stable isotope analysis". PLoS ONE 15(3): E0229398. https://doi.org/10.1371/journal.pone.0229398

Leisner, G. y Leisner, V. 1949: "Varia. Los monumentos megalíticos del mediodía de la Península Ibérica, según los resultados a que han llegado G. y V. Leisner. Conclusión”. Traducción G. Martínez Munilla. Archivo Español de Arqueología XXII, 77: 363-377.

López Padilla, J. A. 2006: "Consideraciones en torno al Horizonte Campaniforme de Transición". Archivo de Prehistoria Levantina XXVI: 193-243.

Trab. Prehist., 78, N. ${ }^{\circ}$ 1, enero-junio 2021, pp. 86-103, ISSN: 0082-5638 https://doi.org/10.3989/tp.2021.12266 
López Padilla, J. A. 2009: "El grupo argárico en los confines orientales del Argar”. En M. S. Hernández Pérez, J. Soler Díaz y J. A. López Padilla (ed.): En los confines del Argar: una cultura de la Edad del Bronce en Alicante en el centenario de Julio Furgús [catálogo exposición]. MARQ-Museo Arqueológico Provincial de Alicante, Diputación Provincial. Alicante: 246-267.

López Padilla, J. A. (ed.) 2014: Cabezo Pardo (San Isidro/Granja de Rocamora, Alicante). Excavaciones arqueológicas en el yacimiento de la Edad del Bronce. Memorias Excavaciones Arqueológicas 6, MARQ-Museo Arqueológico Provincial de Alicante, Diputación de Alicante. Alicante.

López Padilla, J. A. y Jover Maestre, F. J. 2014: “Cabezo Pardo. Una aldea de campesinos en el confín de El Argar". En J. A. López Padilla (ed.): Cabezo Pardo (San Isidro/Granja de Rocamora, Alicante). Excavaciones arqueológicas en el yacimiento de la Edad del Bronce. Memorias Excavaciones Arqueológicas 6, MARQ-Museo Arqueológico Provincial de Alicante, Diputación de Alicante. Alicante: 395409.

López Padilla, J. A.; Jover Maestre, F. J.; Martínez Monleón, S.; Sánchez Lardiés, A.; Luján Navas, A.; Pastor Quiles, M. y Basso Rial, R. 2017: "El Argar alicantino. La Edad del Bronce en el Bajo Segura y Bajo Vinalopó". Tomad y bebed: una copa para un ritual milenario. MARQ-Museo Arqueológico Provincial de Alicante, Diputación de Alicante. Alicante: 65-85.

López Padilla, J. A.; Jover Maestre, F. J.; Martínez Monleón, S.; Sánchez Lardiés, A.; Pastor Quiles, M.; Basso Rial, R. y Luján Navas, A. 2018: "Los toros de arcilla de Laderas del Castillo". En J. A. López Padilla y F. J. Jover Maestre (ed.): Los toros de El Argar: figurillas de arcilla de la Edad de Bronce. MARQ-Museo Arqueológico Provincial de Alicante, Diputación de Alicante. Alicante: 5-19.

Lull Santiago, V. 1983: La "cultura" de El Argar. (Un modelo de estudio de las formaciones económico-sociales prehistóricas). Akal-Universitaria. Barcelona.

Lull Santiago, V. y Risch, R. 1996: "El Estado argárico". Verdolay 7: 97-109.

Lull Santiago, V.; Micó Pérez, R.; Rihuete-Herrada, C. y Risch, R. 2005: "Property relations in the Bronze Age of South-western Europe: an archaeological analysis of infant burials from El Argar (Almeria, Spain)". Proceedings of the Prehistoric Society 71: 247-268.

Lull Santiago, V.; Micó Pérez, R.; Rihuete-Herrada, C. y Risch, R. 2009: "El Argar: la formación de una sociedad de clases". En M. Hernández, J. Soler y J. López Padilla (ed.): En los confines del Argar: una cultura del Bronce en Alicante en el centenario de Julio Furgús [catálogo exposición]. $M A R Q$-Museo Arqueológico Provincial de Alicante, Diputación Provincial. Alicante: 224-245.

Lull Santiago, V.; Micó Pérez, R.; Rihuete-Herrada, C. y Risch, R. 2010: "Límites históricos y limitaciones del conocimiento arqueológico: la transición entre los grupos arqueológicos de Los Millares y El Argar". En P. Bueno, A. Gilman, C. Martin Morales y J. Sánchez Palencia (eds.): Arqueología, sociedad, territorio y paisaje. Estudios sobre prehistoria reciente, protohistoria y transición al mundo romano. En Homenaje a $M^{a}$ Dolores Fernández Posse. Bibliotheca Praehistorica Hispana 28, CSIC. Madrid: 75-94.

Lull Santiago, V.; Micó Pérez, R.; Rihuete-Herrada, C. y Risch, R. 2014: "La Bastida fortification system: new light and new questions on the Early Bronze Age societies in the Western Mediterranean". Antiquity: 88, 340: 395-410. https://doi.org/10.1017/S0003598X00101073

Lull Santiago, V.; Micó Pérez, R.; Rihuete-Herrada, C. y Risch, R. 2015a: "Transition and conflict at the end of the 3rd millennium BC in south Iberia”. En H. Meller, H. W. Arz, R. Jung y R. Risch (eds.): 2200 BC - A climatic breakdown as a cause for the collapse of the old world? 7. Mitteldeutscher Archäologentag (Halle, Saale 2018). Tagungen des Landesmuseums für Tagungen des Landesmuseums für Vorgeschichte Halle 12, 1, Landesamt für Denkmalpflege und Archäologie Sachsen-Anhalt. Halle (Saale).

Lull Santiago, V.; Micó Pérez, R.; Rihuete-Herrada, C. y Risch, R. 2015b: La Bastida y Tira del Lienzo (Totana, Murcia). Ruta Argárica, Guías arqueológicas. Murcia.

Lull Santiago, V.; Micó Pérez, R.; Rihuete-Herrada, C. y Risch, R. 2015c: La Almoloya (Pliego,Murcia). Ruta Argárica, Guías arqueológicas. Murcia.
Lull Santiago, V.; Micó Pérez, R.; Rihuete-Herrada, C.; Risch, R. y Escanilla, N. 2017: "The absolute chronology of Argaric halberds". En J. A. Barceló, I. Bogdanovic y B. Morell (eds.): IberCrono. Cronometrías para la Historia de la Península Ibérica. Actas del Congreso de Cronometrías para la Historia de la Península Ibérica (Barcelona 2016) Vol-2024: 144-162. Barcelona.

Lull Santiago, V.; Micó Pérez, R.; Rihuete-Herrada, C.; Risch, R.; Celdrán Beltrán, E.; Freigeiro Morador, M. I.... y Velasco Felipe C. 2018: "Diez años de 'Proyecto Bastida' (2008-2018): El retrato emergente de una ciudad prehistórica”. XXIV Jornadas de Patrimonio Cultural de la Región de Murcia (Murcia 2018): 317-329. [Murcia].

Martín Socas, D. y Camalich Massieu, M. D. 1982: "La 'cerámica simbólica' y su problemática (aproximación a través de los materiales de la Colección Siret)". Cuadernos de Prehistoria de la Universidad de Granada 7: 267-306.

Martínez Navarrete, M. ${ }^{\text {a }}$. 1989: Una reflexión crítica sobre la Prehistoria española: la Edad delBronce como paradigma. Siglo XXI Editores. Madrid.

Martínez Santa-Olalla, J. y Sáez Martín, B. 1947: "Orígenes anatolioegeos y orientales del Bronce Mediterráneo Hispánico”. En J. Martínez Santa-Olalla, B. Sáez Martín, C. F. Posac, J. A. Sopranis y J. A. del Val: Excavaciones en la ciudad del Bronce Mediterráneo II de la Bastida de Totana (Murcia). Informes y Memorias 16, Ministerio de Educación Nacional. Madrid: 121-158.

Molina Burguera, G. 2003: Fronteras culturales en la prehistoria reciente del sudeste peninsular. La cueva de Los Tiestos (Jumilla. Murcia). Universidad de Alicante-Museo Municipal ‘Jerónimo Molina' de Jumilla. Jumilla.

Molina González, F. 1978: "Definición y sistematización del Bronce tardío y final en el sudeste de la península ibérica”. Cuadernos de Prehistoria de la Universidad de Granada 3: 159-232.

Molina González, F. y Cámara Serrano, J. A. 2004: "La cultura de El Argar en el área occidental del Sureste”. En L. Hernández y M. Hernández (eds.): La Edad del Bronce en tierras valencianas y zonas limitrofes. Diputación Provincial de Alicante, Instituto Alicantino de Cultura Juan Gil-Albert, Ayuntamiento de Villena. Villena, Alicante: 455- 470 .

Molina González y Pareja López, E. 1975: Excavaciones en la Cuesta del Negro (Purullena, Granada). Campaña de 1971. Excavaciones Arqueológicas en España 86, Ministerio de Cultura. Madrid.

Molina González, F.; Cámara Serrano, J. A.; Capel Martínez, J.; Nájera Colino, T. y Sáez Pérez, L. 2004: "Los Millares y la periodización de la Prehistoria Reciente del Sureste". III Simposio de Prehistoria de la Cueva de Nerja. Las primeras sociedades metalúrgicas en Andalucia: 142-158. Nerja, Málaga.

Molina González, F.; Cámara Serrano, J. A.; Afonso Marrero, J. y Nájera Colino, T. 2014: "Las sepulturas del Cerro de la Virgen (Orce, Granada). Diferencias cronológicas y diferencias sociales". Revista Atlántica-Mediterránea 16: 121-142.

Molina González, F.; Cámara Serrano, J. A.; Dorado Alejos, A. y Villaroya Arín, M. 2017: "El fenómeno campaniforme en el Sudeste de la península ibérica: el caso del Cerro de la Virgen (Orce, Granada)". En V. S. Gonçalves (ed.): Sinos e Taças. Junto ao Oceano e mais longe. Aspectos da presença campaniforme na Península Ibérica. Estudos e Memórias 10, UNIARQ-Centro de Arqueologia da Universidade de Lisboa. Lisboa: 258-275.

Montero Ruiz, I.; Murillo-Barroso, M. y Hook, D. 2019: "La producción de bronces durante El Argar: Frecuencia y criterios de uso". Boletín del Museo Arqueológico Nacional 38: 9-26.

Odriozola Lloret, C. P. 2019: "La decoración con rellenos de pasta en las cerámicas campaniformes". En G. Delibes y E. Guerra (eds.): ;Un brindis por el príncipe! el vaso campaniforme en el interior de la Península Ibérica (2500-2000 A.C.). [catálogo exposición] II, Comunidad de Madrid, Museo Arqueológico Regional. Madrid: 11-22.

Pascual Benito, J. Ll. 1988: "Les coves sepulcrals de l'Alberri (Cocentaina): el poblament de la Vall Mitjana del riu d'Alcoi durant el III mil·lenari BC". Saguntum 21: 109-168.

Patterson, Th. C. 2003: Marx's ghost. Conversations with archaeologists. Berg ed. Oxford-Nueva York.

Trab. Prehist., 78, N. ${ }^{\circ}$ 1, enero-junio 2021, pp. 86-103, ISSN: 0082-5638

https://doi.org/10.3989/tp.2021.12266 
Ramos Fernández, R. 1984: "Memoria de las excavaciones realizadas en el Promontori de Elche durante las campañas 1980-81". Noticiario arqueológico hispánico 19: 9-33.

Risch, R. 2002: Recursos naturales, medios de producción y explotación social. Un análisis económico de la industria lítica de Fuente Álamo (Almería), 2250-1400 ANE. Iberia Archaeologica 3, Philipp von Zabern. Maguncia.

Ros Sala, M. M. 1986: "Datos para el estudio del Bronce Tardío y Final en el Valle del Guadalentin: el poblado de "Las Cabezuelas" (Totana, Murcia)". Anales de Prehistoria y Arqueología de la Universidad de Murcia 2: 39-47.

Ruiz Sanz, M. J. 1998: "Excavaciones de urgencia en el poblado de Santa Catalina del Monte (Verdolay, Murcia)". Memorias de Arqueología 7 , Consejería de Cultura. Murcia: 78- 116.

Sangmeister, E. 1963: "La civilisation du vase campaniforme". Les civilisations atlantiques du néolithique à l'Age du Fer. Actes du premier colloque atlantique (Brest 1961): 25-56. Rennes.

Schmidt, H. 1915: "Estudios acerca de los principios de la Edad de los Metales en España". Memoria de la Comisión de Investigaciones Paleontológicas y Prehistóricas 8, Junta para Ampliación de Estudios e Investigaciones Científicas, Museo Nacional de Ciencias Naturales. Madrid.

Schubart, H. 1975: "Cronología relativa de la cerámica sepulcral en la cultura de El Argar". Trabajos de Prehistoria 32, 1: 79-92.

Schubart, H. 1976: "Relaciones mediterráneas de la cultura de El Argar". Zephyrus XXVI-XXVII: 331-342.

Schubart, H. 2004: "La cerámica argárica en la estratigrafía de Fuente Álamo: campañas de 1977-1982". Spal 13: 35-82. https://doi. org/10.12795/spal.2004.i13.02

Schubart, H. 2012: Die gräber von Fuente Álamo. Madrider Beiträge 32, Reichert Verlag. Wiesbaden.

Schubart, H. 2014: "Die bronzezeitliche Keramik aus der Probegrabung auf dem Siedlingsplateau von El Argar". En H. Schubart y D. Marzoli: "El Argar (Antas, Almería)" (mit Beiträgen von C. Liesau, H.-G. Bachmann, R. Pozo Marín). Madrider Mitteilungen 55: 64-83.

Schubart, H. y Arteaga Matute, O. 1986: "Fundamentos arqueológicos para el estudio socioeconómico y cultural del área de El Argar”. Actas del Congreso 'Homenaje a Luis Siret' (1934-1984). Cuevas de Almanzora (1984): 289-307. Sevilla.

Schubart, H. y Ulreich, H. 1991: Die Funde der Südostspanischen Bronzezeit aus der Sammlung Siret. Madrider Beiträge 17, Philipp von Zabern. Maguncia.

Schubart, H.; Pingel, V. y Arteaga Matute, O. 2000: Fuente Álamo. Las excavaciones arqueológicas 1977-1991 en el poblado de la Edad del Bronce. Junta de Andalucía, Consejería de Cultura. Sevilla.

Schubart, H.; Marzoli, D. y Liesau Von Lettow-Vorbeck, C. 2014: “Absolute Chronologie". En H. Schubart y D. Marzoli: "El Argar (Antas, Almería)" (mit Beiträgen von C. Liesau, H.-G. Bachmann, R. Pozo Marín). Madrider Mitteilungen 55: 103-106.

Schüle, W. 1980: Orce und Galera. Zwei Siedlungen aus dem 3. bis 1. Jahrtausend v. Chr. Im Südosten der Iberischen Halbinsel. Philipp von Zabern. Maguncia.
Schuhmacher, T. X. y Schubart, H. 2003: Fuente Alamo: die siedlungskeramik der grabungen 1985-1991: untersuchungen zur chronologie und zum siedlungsschema der El Argar-Kultur; stratigraphisch geordnete keramik der El Argar-Zeit aus den Grabungen 1977-1982. Iberia Archaeologica 4, Philipp von Zabern. Maguncia.

Simón García, J. L. 1988: "Catálogo y estudio de los fondos prehistóricos (del V al II milenio) de los Museos de la Marina Alta”. Ayudas a la Investigación 1986-1987 III, Instituto Juan Gil-Albert. Alicante: 105-122.

Simón García, J. L. 1997: "La 1lleta: asentamiento litoral en el Mediterráneo occidental de la Edad del Bronce". En M. Olcina Doménech (ed.): La Illeta deis Banyets (El Campello, Alicante). Estudios de la Edad del Bronce y Época ibérica. Serie Mayor 1, MARQ-Museo Arqueológico Provincial de Alicante, Diputación Provincial de Alicante. Alicante: 47-132.

Simón García, J. L. 1998: La metalurgia prehistórica valenciana. SIP Serie de Trabajos Varios 93. Valencia.

Siret, E. y Siret, L. 1890: Las primeras edades del metal en el sudeste de España. Tipografía de Heinrich y Cía. Barcelona.

Siret, L. 1907 [1994]: Orientales y occidentales en España en los tiempos prehistóricos. Arráez. Almería.

Siret, L. 1913: Questions de chronologie et d'ethnographie ibériques I. De la fin du quaternaire à la fin du bronze. Paul Geuthner. Paris.

Soler Díaz, J. (ed.) 2006: La ocupación prehistórica de la "Illeta dels Banyets" (El Campello, Alicante). Serie Mayor 5, MARQ-Museo Arqueológico Provincial de Alicante, Diputación Provincial de Alicante. Alicante.

Soler García, J. M. 1981: El Eneolitico en Villena (Alicante). Serie Arqueológica 7, Dpto. de Historia Antigua. Universidad de Valencia. Valencia.

Tarradell Mateu, M. 1946: "Sobre la delimitación geográfica de la cultura de El Argar”. II Congreso Arqueológico del Sudeste Español (Murcia, Albacete 1946): 139-141. Cartagena

Tarradell Mateu, M. 1963: El País Valenciano del Neolítico a la iberización. Ensayo de sintesis. Anales de la Universidad de Valencia XXXVI. Valencia.

Tarradell Mateu, M. 1965: "El problema de las diversas áreas culturales de la península ibérica en la Edad del Bronce”. En E. Ripoll (ed.): Miscelánea en homenaje al Abate Henri Breuil (1877-1961) II, Diputación Provincial de Barcelona, Instituto de Prehistoria y Arqueología. Barcelona: 423-430.

Trigger, B. 1990: A history of archaeological thought. Cambridge University Press. Cambridge.

Whittlesey, D. 1920: The Earth and the State. Henry Holt and Co. New York.

Wissler, C. 1927: "The culture-area concept in Social Anthropology". American Journal of Sociology 32, 6: 881-891. https:/www.jstor.org/ stable/2765396 